\title{
Macroglial Plasticity and the Origins of Reactive Astroglia in Experimental Autoimmune Encephalomyelitis
}

\author{
Fuzheng Guo, ${ }^{1}$ Yoshiko Maeda, ${ }^{1}$ Joyce Ma, ${ }^{1}$ Monica Delgado, ${ }^{1}$ Jiho Sohn, ${ }^{1}$ Laird Miers, ${ }^{1}$ Emily Mills Ko, ${ }^{1}$ \\ Peter Bannerman, ${ }^{1}$ Jie Xu, ${ }^{1}$ Yazhou Wang, ${ }^{1}$ Chengji Zhou, ${ }^{1}$ Hirohide Takebayashi, ${ }^{2}$ and David Pleasure ${ }^{1}$ \\ ${ }^{1}$ Institute for Pediatric Regenerative Medicine, University of California, Davis, School of Medicine and Shriners Hospital, Sacramento, California 95817, \\ and ${ }^{2}$ Department of Morphological Neural Science, Graduate School of Medical Sciences, Kumamoto University, Kumamoto 860-8556, Japan
}

Accumulations of hypertrophic, intensely glial fibrillary acidic protein-positive $\left(\mathrm{GFAP}^{+}\right)$astroglia, which also express immunoreactive nestin and vimentin, are prominent features of multiple sclerosis lesions. The issues of the cellular origin of hypertrophic GFAP ${ }^{+}$I vimentin ${ }^{+} /$nestin ${ }^{+}$"reactive" astroglia and also the plasticities and lineage relationships among three macroglial progenitor populations - oligodendrocyte progenitor cells (OPCs), astrocytes and ependymal cells-during multiple sclerosis and other CNS diseases remain controversial. We used genetic fate-mappings with a battery of inducible Cre drivers (Olig2-Cre-ER ${ }^{\mathrm{T} 2}$, GFAP-Cre-ER ${ }^{\mathrm{T} 2}$, FoxJ1Cre-ER ${ }^{\mathrm{T} 2}$ and Nestin-Cre-ER ${ }^{\mathrm{T} 2}$ ) to explore these issues in adult mice with myelin oligodendrocyte glycoprotein peptide-induced experimental autoimmune encephalomyelitis (EAE). The proliferative rate of spinal cord OPCs rose fivefold above control levels during EAE, and numbers of oligodendroglia increased as well, but astrogenesis from OPCs was rare. Spinal cord ependymal cells, previously reported to be multipotent, did not augment their low proliferative rate, nor give rise to astroglia or OPCs. Instead, the hypertrophic, vimentin ${ }^{+} /$ nestin $^{+}$, reactive astroglia that accumulated in spinal cord in this multiple sclerosis model were derived by proliferation and phenotypic transformation of fibrous astroglia in white matter, and solely by phenotypic transformation of protoplasmic astroglia in gray matter. This comprehensive analysis of macroglial plasticity in EAE helps to clarify the origins of astrogliosis in CNS inflammatory demyelinative disorders.

\section{Introduction}

Multiple sclerosis affects $>300,000$ individuals in the United States. Oligodendroglia are depleted from acute multiple sclerosis plaques. Subsequent remyelination is often incomplete, despite the continued presence of oligodendroglial progenitor cells (OPCs) in and around plaques (Miron et al., 2011). Another consistent feature of multiple sclerosis lesions is the accumulation of hypertrophic reactive astroglia; these immunostain intensely for glial fibrillary acidic protein (GFAP) and also display immunoreactive nestin and vimentin (Voskuhl et al., 2009). Bromodeoxyuridine labeling (Alonso, 2005; Sellers et al., 2009), Olig2 immunohistochemistry (Buffo et al., 2005; Cassiani-Ingoni et al., 2006; Magnus et al., 2007, 2008), and genetic fate-mapping (Tatsumi et al., 2008) suggested OPCs contribute to astrogliosis in multiple sclerosis and other CNS disorders. Adding to the

\footnotetext{
Received April 7, 2011; revised June 3, 2011; accepted June 30, 2011.

Author contributions: F.G., J.H.-Y.M., and D.P. designed research; F.G., Y.M., J.H.-Y.M., M.D., J.S., L.M., E.M.K., P.B., J.X., and Y.W. performed research; J.S. and H.T. contributed unpublished reagents/analytic tools; F.G., Y.M., J.H.-Y.M., M.D., J.S., P.B., Y.W., C.Z., H.T., and D.P. analyzed data; F.G. and D.P. wrote the paper.

This work was supported by NIH Grant R01NS025044 (D.P., E.M.K.,P.B., M.D.), National Multiple Sclerosis Society Grant RG 4397-A-5 (D.P.), the Shriners Hospitals for Children (F.G., J.M., D.P., P.G., L.M.), and the California Institute for Regenerative Medicine (F.G., J.M., D.P.). We thank F. M. Vaccarino (Yale University), A. J. Eisch (University of Texas), B. L. M. Hogan (Duke University) and S. J. Pleasure (University of California, San Francisco) for providing GFAP-Cre-ER ${ }^{\mathrm{T} 2}$, Nestin-Cre-ER ${ }^{\mathrm{T} 2}$, Foxj1-Cre-ER ${ }^{\mathrm{T} 2}$, and Nestin-GFP mice, respectively.

Correspondence should be addressed to David Pleasure, Institute for Pediatric Regenerative Medicine, University of California, Davis School of Medicine, c/o Shriners Hospitals for Children Northern California, 2425 Stockton Boulevard, Sacramento, CA 95817. E-mail: david.pleasure@ucdmc.ucdavis.edu.

DOI:10.1523/JNEUROSCI.1759-11.2011

Copyright $\odot 2011$ the authors $\quad 0270-6474 / 11 / 3111914-15 \$ 15.00 / 0$
}

credibility of this hypothesis, fate-mapping with Plp-Cre-ER ${ }^{\mathrm{T} 2}$ and constitutive NG2-Cre transgenes demonstrated a precursor/ product relationship between OPCs and astroglia in neonatal mouse spinal cord (Zhu et al., 2008; Guo et al., 2009). However, OPC fate-mapping with Pdgfra-Cre-ER ${ }^{\mathrm{T} 2}$ or NG2-Cre-ER ${ }^{\mathrm{T} 2}$ in adult mice failed to support a precursor-product relationship between OPCs and reactive astroglia during experimental autoimmune encephalomyelitis (EAE) or after spinal cord trauma (Tripathi et al., 2010; Komitova et al., 2011). We now report that most gray matter astroglia in normal adult spinal cord express Olig2; hence, Olig2-Cre-ER fate mapping and Olig2 immunohistochemistry, in the absence of additional studies, is not an unequivocal means by which to explore lineage relationships between OPCs and astroglia. By combining Olig2-Cre-ER fate mapping with OPC bromodeoxyuridine (BrdU) labeling, we demonstrate that though OPC proliferation and production of oligodendroglia increase in the EAE spinal cord, OPCs are not a significant source for spinal cord astroglia in this multiple sclerosis model.

If reactive astroglia in CNS inflammatory demyelinative disorders are not derived from OPCs, what is their origin? Previous studies had shown that reactive astroglia originate from local proliferation of resident astrocytes in CNS traumatic injury (Bush et al., 1999; Faulkner et al., 2004; Myer et al., 2006) and EAE (Voskuhl et al., 2009). 1,1'-Dioctadecyl$3,3,3^{\prime}, 3^{\prime}$-tetramethylindocarbocyanine perchlorate (DiI) labeling studies suggested the derivations of astroglia, oligodendroglia, and neurons from ependymal cells in EAE (Brundin et al., 2003; Danilov 
et al., 2006). Fate-mapping with FoxJ1-Cre-ER ${ }^{\mathrm{T} 2}$ showed that ependyma give rise to both astroglia and oligodendroglia after physical trauma to the spinal cord (Meletis et al., 2008; Barnabé-Heider et al., 2010). By contrast, we found that the normally low rate of proliferation of ependymal cells in adult murine spinal cord did not increase in EAE, nor were reactive astroglia labeled by FoxJ1-Cre$\mathrm{ER}^{\mathrm{T} 2}$ or Nestin-Cre-ER ${ }^{\mathrm{T} 2}$ fate-mapping. Instead, our fate mapping, BrdU incorporation, and stereological quantification data demonstrated that reactive astrocytes originated solely from resident quiescent astrocytes, and that different mechanisms contributed to the formation of reactive astroglia in spinal gray and white matter, i.e., reactive astrocytes were derived by both hypertrophy and hyperplasia of fibrous astroglia in white matter, but solely by phenotypic transformation of protoplasmic astroglia in gray matter. Our study provides a comprehensive view of the plasticity of OPCs, astrocytes and ependymal cells in the inflamed adult spinal cord.

\section{Materials and Methods}

Animals. Olig2-Cre-ER, GFAP-Cre-ER ${ }^{\mathrm{T} 2}$, Nestin-Cre-ER ${ }^{\mathrm{T} 2}$ and FoxJ1Cre-ER ${ }^{\mathrm{T} 2}$ transgenic mice (Takebayashi et al., 2002; Ganat et al., 2006; Lagace et al., 2007; Rawlins et al., 2007) were crossed to Rosa26-loxPSTOP-loxP-EYFP reporter transgenic mice (Srinivas et al., 2001) to yield OCER, GCER, NCER, and FCER transgenic mice, respectively, which carried an heterozygous Cre transgene and homozygous reporter transgenes. GFAP-GFP transgenic mice (Zhuo et al., 1997) were purchased from Jackson Laboratory (stock \#003257). Nestin-GFP transgenic mice (Yamaguchi et al., 2000) were provided to us by S. Pleasure (University of California, San Francisco). All mice were maintained on a C57BL/6 background. Both males and females were used in this study.

Tamoxifen induction and BrdU (or 5-ethynyl-2' -deoxyuridine) administration. Tamoxifen (TM) (T5648; Sigma-Aldrich) was prepared and administered as described previously (Guo et al., 2010); 2- to 3-month postnatal OCER, GCER, and FCER mice and 4- to 5-month postnatal NCER mice were treated with TM for $5 \mathrm{~d}$, twice a day via intraperitoneal injection. The reporter EYFP expression was designated as O-EYFP, G-EYFP, N-EYFP, and F-EYFP to indicate driving by Olig2-Cre-ER, GFAP-Cre-ER ${ }^{\mathrm{T} 2}$, Nestin-Cre-ER ${ }^{\mathrm{T} 2}$, and FoxJ1-Cre-ER ${ }^{\mathrm{T} 2}$ transgenes, respectively. For pulse labeling, BrdU [or 5-ethynyl-2'-deoxyuridine (EdU), indicated in Results] was injected intraperitoneally at $100 \mathrm{mg} / \mathrm{kg}$ body weight, and the mice were analyzed $2 \mathrm{~h}$ later. For long-term labeling, mice were given $\mathrm{BrdU}$ in their drinking water $(1 \mathrm{mg} / \mathrm{ml})$ and also received daily BrdU by intraperitoneal injection ( $100 \mathrm{mg} / \mathrm{kg}$ body weight).

EAE induction and clinical scoring. Thirty to forty days after TM administration, mice were immunized with MOG peptide 35-55 to induce EAE, and clinical scores were assessed daily according to our previous methods (Soulika et al., 2009). Briefly, mice were injected subcutaneously with $300 \mu \mathrm{g}$ of rodent MOG peptide (amino acids 35-55) in CFA containing $5 \mathrm{mg} / \mathrm{ml}$ killed Mycobacterium tuberculosis on day 0, with intraperitoneal administration of $200 \mathrm{ng}$ of pertussis toxin on days 0 and 2. "CFA control mice" received CFA and pertussis toxin, but no MOG peptide. The mice were weighed and scored daily. Neurological deficits were assessed on a five-point scale (limp tail or waddling gait $=1$; limp tail and waddling gait $=2$; single limb paresis and ataxia 2.5; double limb paresis $=3$; single limb paralysis and paresis of second limb $=3.5$; full paralysis of 2 limbs $=4$; moribund $=4.5$; and death $=5$ ). Mice were on days 14 (D14, same thereafter), 21, 28, 35, 56, or 65 postimmunization with MOG peptide in CFA (EAE mice) or CFA alone (CFA control mice). Only mice with clinical scores of 2.0 or above were analyzed.

Tissue preparation. Mice were anesthetized with ketamine/xylazine, and then perfused transcardially with PBS, followed by $4 \%$ PFA. Lumbar spinal cord was harvested, postfixed in 4\% PFA either at room temperature (RT) for $2 \mathrm{~h}$ or $4^{\circ} \mathrm{C}$ overnight, cryopreserved in $30 \%$ sucrose overnight, and embedded in OCT. Twenty micrometer frozen transverse sections were cut on a Leica cryostat.

Immunohistochemistry. Frozen sections were air-dried, then blocked with PBS containing $0.1 \%$ Tween 20 and 5\% donkey serum for $1 \mathrm{~h}$ at RT. The sections were incubated with primary antibodies at $4^{\circ} \mathrm{C}$ overnight, followed by $2 \mathrm{~h}$ incubation at RT with secondary antibody. DAPI was used to label nuclei, and the sections were mounted with Vectashield (Vector Laboratories; H-1000) and subjected to confocal microscopic analysis and imaging. For BrdU immunostaining, sections were prelabeled as above, postfixed with $2 \%$ PFA in $1 \times$ PBS at RT for $15 \mathrm{~min}$, and then DNA was denatured in $2 \mathrm{~N} \mathrm{HCl}$ at $37^{\circ} \mathrm{C}$ for $45 \mathrm{~min}$, followed by BrdU primary antibody incubation. For EdU labeling, the protocol from kit C10084, from Invitrogen, was used to develop EdU signals. The primary antibodies used in this study were as follows: Olig2 (R\&D Systems, \#AF2418, goat, 1:100), Olig2 (IBL, \#18953, rabbit, 1:100), NG2 (Millipore, \#AB5320, rabbit, 1:300), mature oligodendrocyte marker Clone CC1 (Calbiochem, \#OP80, mouse, 1:200), Nestin (Santa Cruz Biotechnology, \#sc-21249, goat, 1:50), GFAP and Vimentin (from Dr. V. Lee, University of Pennsylvania, Philadelphia, PA; 1:100 and 1:500), HuC/D (Invitrogen, \#A21271, mouse, 1:100), NeuN (Millipore, \#MAB377, mouse, 1:500), Sox2 (Millipore, \#AB5603, rabbit, 1:200), Sox10 (Santa Cruz Biotechnology, \#sc-17342, goat, 1:100), BrdU (Santa Cruz Biotechnology, \#sc70441, rat, 1:50), EYFP (Rockland, \#600-102-215, goat or \#600-402-215, rabbit, 1:200), Ibal (Wako, \#019-19741, 1:1000). All secondary antibodies were DyLight 488- or DyLight549-conjugated (Fab)2 fragments (from Jackson ImmunoResearch).

Microscopy and quantification. A Nikon Eclipse C1 laser scanning confocal microscope was used to image mounted slides. Nikon EZ-C1 3.90 FreeViewer was used to create single-channel views, merged views, and orthogonal views of images. We considered two antigens as colocalized only if colocalization extended from the top to bottom of the $z$-plane images. For cell counting, 6 sections with $200 \mu \mathrm{m}$ apart from each animal (three to five animals for each time point) were examined. Stereological quantification of $\mathrm{GFP}^{+}$astroglia in GFAP-GFP EAE and CFA control mice was conducted as previously described (Guo et al., 2009). All counting data were expressed as mean $\pm \mathrm{SD}$. Statistical significance was determined using the two-tail Student's $t$ test.

\section{Results}

\section{Identity of Olig2-expressing cells in the normal adult spinal cord}

Cre-mediated recombination of a fate-marker transgene (e.g., Rosa-loxP-STOP-loxP-EYFP) in knock-in Olig2-Cre-ER mice would be predicted to occur only in cells that express Olig2 at the time that tamoxifen is administered. We therefore used Olig2 antibodies to evaluate the distribution of Olig2 in the adult mouse spinal cord. We used embryonic day 14.5 (E14.5) spinal cords harvested from homozygous Olig2-Cre-ER mice [i.e., Olig2 knock-out (KO) mice] (Takebayashi et al., 2002) and wildtype (WT) littermates to evaluate the specificity of Olig2 antibodies (see Materials and Methods). In E14.5 WT spinal cord, both goat and rabbit Olig2 antibodies yielded identical nuclear staining patterns (Fig. $1 A$ ), and the immunostaining signals were completely abolished in spinal cord of an Olig2 KO littermate (Fig. $1 B$ ). We thus concluded that the tissue binding of these Olig2 antibodies faithfully reflected endogenous Olig2 protein expression.

As previously reported (Ligon et al., 2006), almost all NG2 ${ }^{+}$ OPCs (Fig. $1 E$ ) and $\mathrm{CC}^{+}$mature oligodendrocytes (Fig. $1 E$ ) in adult spinal cord expressed nuclear Olig2 in both white matter (WM) and gray matter (GM), and $\mathrm{NG}^{+}$OPCs (Fig. $1 F$ ) and $\mathrm{CC}^{+}{ }^{+}$mature oligodendrocytes (Fig. $1 F$ ) comprised the majority of Olig2-expressing cells. Unexpectedly, however, GFAP ${ }^{+}$astrocytes in the GM, but not WM, proved also to be nuclear Olig $2^{+}$in normal adult mouse spinal cord (Fig. $1 E$ ). Double immunohistochemistry with the astroglial marker GFAP and Olig2 in normal adult spinal cord revealed extensive cellular colocalization (Fig. $1 D$, arrowheads) in GM; $80.5 \pm 4.1 \%$ (mean $\pm \mathrm{SD}$, and thereafter) of $\mathrm{GM} \mathrm{GFAP}^{+}$cells were Olig2 ${ }^{+}$, and Olig2 ${ }^{+}$/ $\mathrm{GFAP}^{+}$cells comprised $18.2 \pm 3.8 \%$ of total GM Olig2 ${ }^{+}$cells (Fig. $1 E, F)$. In contrast, no coimmunolabeling of Olig2 and 

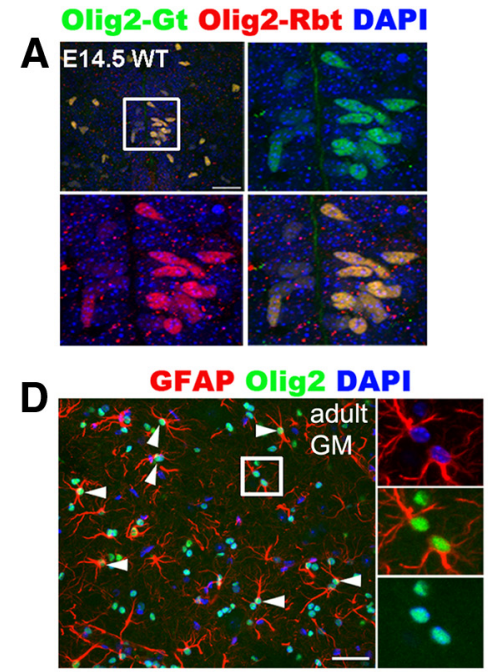

Olig2 GFAP DAPI
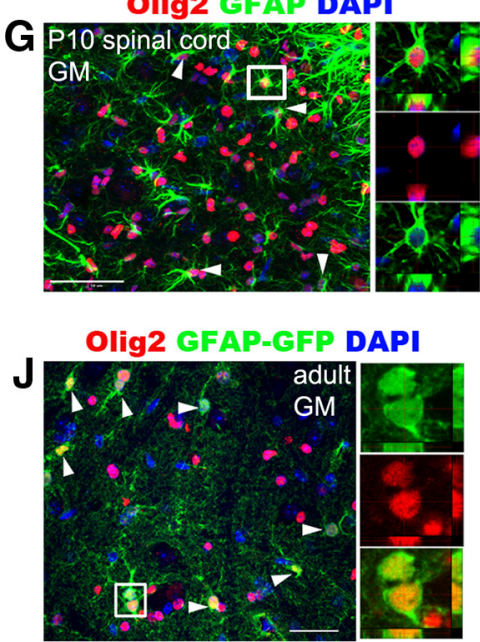

Olig2-Gt Olig2-Rbt DAPI

B E14.5 Olig2 KO

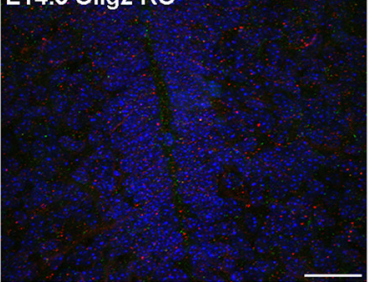

$\mathbf{E}$

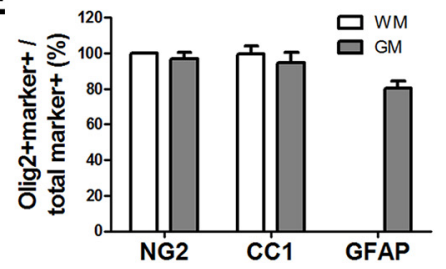

$\mathrm{H}$

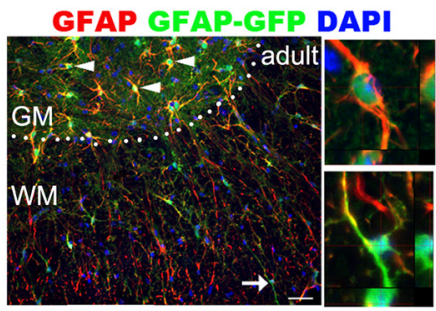

K

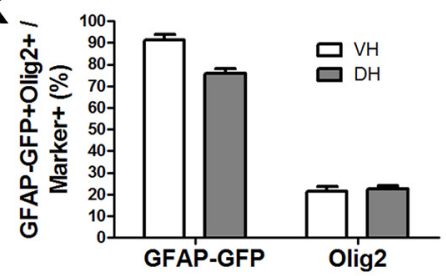

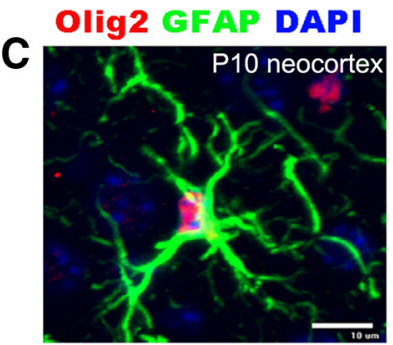

F

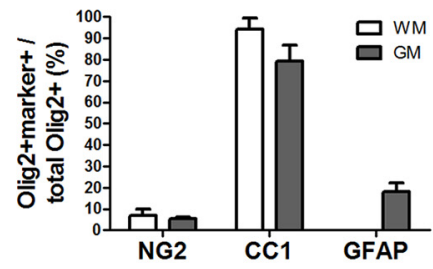

Olig2 GFAP-GFP DAPI

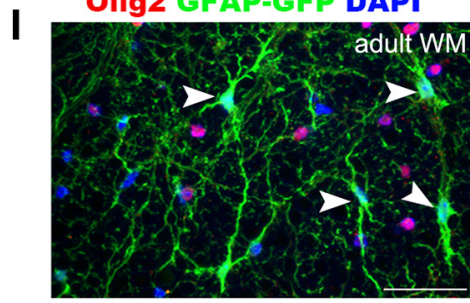

$\mathbf{L}$

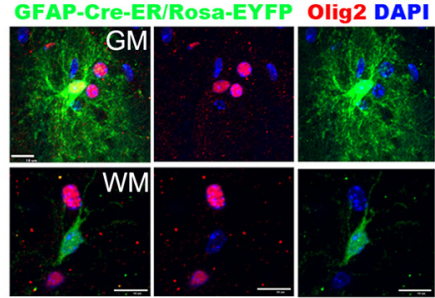

Figure 1. Olig2 expression by astrocytes in adult spinal cord. $\boldsymbol{A}, \boldsymbol{B}$, Immunostaining of goat (Gt) and rabbit (Rbt) 0lig2 antibodies on the embryonic day 14.5 (E14.5) spinal cords from WT (A) and Olig2 KO (B) embryos. Note that Olig2 signals was completely absent from 0 lig2 $\mathrm{KO}$ spinal cord. C, Image from postnatal day 10 (P10) neocortex showing that GFAP ${ }^{+}$astrocytes expressed 0 lig2. D, Colabeling of GFAP and Olig2 in adult WT spinal cord. Boxed area is shown in higher magnification on the right. $E$, Percentage of NG2 ${ }^{+}$oligodendroglial progenitor cells (OPCS), $\mathrm{CC} 1{ }^{+}$mature oligodendrocytes and GFAP ${ }^{+}$astrocytes that express 0 lig2 in both gray matter (GM) and white matter (WM) of adult spinal cord. $F$, Percentage of 0lig2 ${ }^{+}$cells that express NG2, CC1 and GFAP in both GM and WM of adult spinal cord. $\mathbf{G}$, Olig2 expression in astrocytes in GM of P10 spinal cord. Boxed area is shown in higher magnification on the right. $\boldsymbol{H}$, Reporter GFP expression reflects the endogenous GFAP expression in GFAP-GFP transgenic mice. Cell in WM marked by arrow is shown in higher power on the right. I, No overlap of GFAP-GFP with Olig2 in spinal WM. Arrowheads point to GFAP-GFP ${ }^{+}$cells. J, Colabeling of GFAP-GFP reporter and Olig2 in adult spinal cord GM. Boxed area was shown in higher magnification in the right. $K$, Quantification of GFAP-GFP and Olig2 in the ventral horn (VH) and dorsal horn (DH) of adult GFAP-GFP mice. L, GM (top), but not WM (bottom) EYFP ${ }^{+}$cells in GFAP-Cre-ERT2/Rosa-EYFP (GCER) transgenic mice treated with TM express Olig2. Arrowheads in $\mathbf{D}, \mathbf{G}, \boldsymbol{H}$, and $\boldsymbol{J}$ indicate double-positive cells. Scale bars: $\boldsymbol{A}, \boldsymbol{B}, \boldsymbol{D}, \mathbf{G}, \boldsymbol{H}-\boldsymbol{J}, 50 \mu \mathrm{m} ; \boldsymbol{C}, \mathbf{L}, 10 \mu \mathrm{m}$.

GFAP was observed in the normal adult spinal cord WM (Fig. $1 E, F)$. The Olig2 expression level in $\mathrm{GFAP}^{+}$astrocytes was similar to that in GFAP-negative cells, as assessed by immunoreactive intensity (Fig. $1 \mathrm{D}$ ). Some astroglia in postnatal day 10 (P10) neocortex expressed Olig2 (Fig. 1C), a result consistent with a prior report (Marshall et al., 2005). GM GFAP ${ }^{+}$ astrocytes in P10 spinal cord also expressed Olig2, but at a lower frequency than in the adult (Fig. 1G, arrowheads). To confirm astroglial Olig2 expression, we used GFAP-GFP transgenic mice, in which astroglial visualization was enhanced by means of their cytoplasmic expression of GFP. In the adult spinal cord of GFAP-GFP mice, $97.4 \pm 4.3 \%$ of $\mathrm{GFP}^{+}$cells were $\mathrm{GFAP}^{+}$, and $95.8 \pm 4.9 \%$ of $\mathrm{GFAP}^{+}$cells were $\mathrm{GFP}^{+}$(Fig. $1 \mathrm{H}$ ), indicating the fidelity with which GFP expression reflected endogenous GFAP promoter activity in this transgenic line. Consistent with the results we had obtained with GFAP immunostaining, no GFAP-GFP ${ }^{+}$cells ex- pressed Olig2 in spinal cord WM (Fig. 1I, arrowheads), whereas in GM, the majority of GFAP-GFP ${ }^{+}$cells were Olig2 ${ }^{+}$ (Fig. $1 \mathrm{~J}$, arrowheads); $91 \pm 2.7 \%$ and $76 \pm 2.2 \%$ of GFAP$\mathrm{GFP}^{+}$astrocytes expressed Olig2 in ventral horn $(\mathrm{VH})$ and dorsal horn $(\mathrm{DH})$ of the spinal cord, respectively (Fig. $1 \mathrm{~K}$ ). Similar to our GFAP/Olig2 coimmunolabeling, $\sim 21 \%$ of total $\mathrm{GM}_{\text {Olig } 2}{ }^{+}$cells were GFAP-GFP ${ }^{+}$astrocytes (Fig. $1 \mathrm{~K}$ ). Furthermore, when astrocytes were labeled with reporter EYFP by tamoxifen administration to normal adult GFAP-Cre-ER ${ }^{\mathrm{T} 2}$ / Rosa-loxP-STOP-loxP-EYFP (GCER) mice, reporter EYFP ${ }^{+}$ cells with characteristic astrocytic morphology, i.e., complex bushy distal processes (Bushong et al., 2002) in spinal cord GM (Fig. $1 \mathrm{~L}$, top), but not WM (Fig. $1 \mathrm{~L}$, bottom), were coimmunolabeled with Olig2. Collectively, these results indicate that most GM GFAP ${ }^{+}$astrocytes, as well as OPCs and oligodendroglia, express Olig2 in the normal adult mouse spinal cord. 

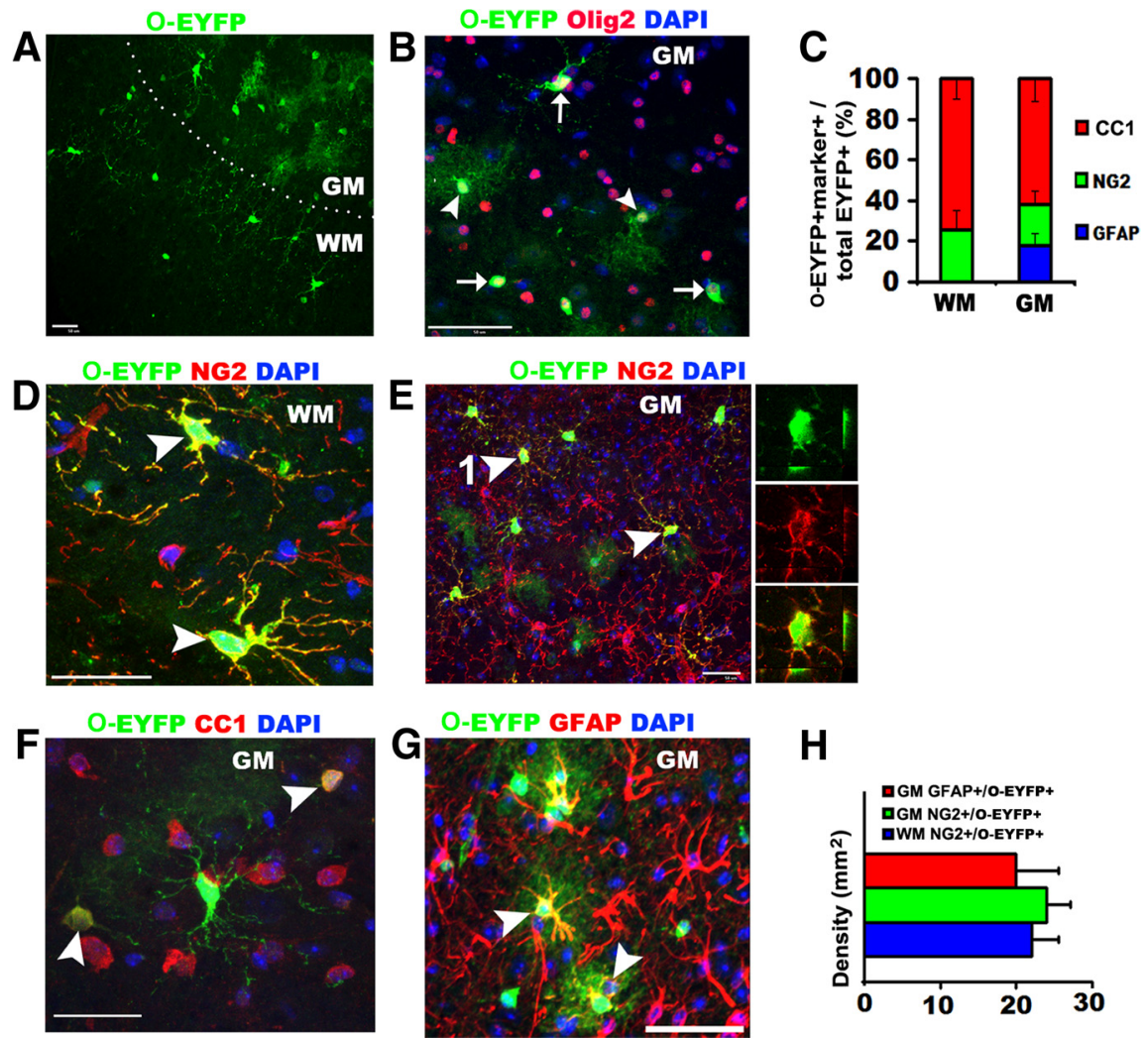

H

Figure 2. Genetic labeling of Olig2-expressing cells in adult spinal cord. A, At 5 d post-TM treatment of Olig2-Cre-ER/Rosa-loxPSTOP-IOXP-EYFP (OCER) mice, 0 -EYFP ${ }^{+}$cells were scattered throughout spinal cord GM and WM. $\boldsymbol{B}$, Image showing that all EYFP ${ }^{+}$ cells had endogenous Olig2 expression. Arrows point to cells that have oligodendroglial morphology, and arrowheads point to cells that have characteristics of astrocytic morphology, i.e., "bushy" distal processes. C, Histogram of proportions of CC1, NG2 and GFAP-positive cells among total 0 -EYFP ${ }^{+}$cells in WM and GM of adult OCER mice $5 \mathrm{~d}$ post-TM. $\boldsymbol{D}-\boldsymbol{F}$, Representative confocal images showing that $\mathrm{NG}_{2}{ }^{+} \mathrm{OPCs}$ and $\mathrm{CC}^{+}$mature oligodendrocytes in both WM and $\mathrm{GM}$ become labeled with 0 -EFYP. Arrowheads point to double-positive cells. Cell marked by arrowhead 1 in $\boldsymbol{E}$ is shown in higher-magnification channels on the right. $G, G M$ $\mathrm{GFAP}^{+}$astrocytes are labeled with EYFP (arrowheads). $\boldsymbol{H}$, Histograms showing the densities of 0 -EYFP ${ }^{+} / \mathrm{GFAP}^{+}$and 0 -EYFP ${ }^{+} /$ $\mathrm{NG2}{ }^{+}$cells. Scale bars, $50 \mu \mathrm{m}$.

Genetic labeling of Olig2-expressing cells and their normal fates in adult spinal cord

Five days post-tamoxifen treatment (post-TM) to mice carrying both knock-in Olig2-Cre-ER (Takebayashi et al., 2002) and Rosa-loxP-STOP-loxP-EYFP reporter (Srinivas et al., 2001) transgenes (OCER mice), $\mathrm{O}-\mathrm{EYFP}^{+}$cells were scattered throughout the spinal cord in both GM and WM (Fig. $2 A$ ). All of these O-EYFP ${ }^{+}$ cells had nuclear Olig2 immunoreactivity (Fig. $2 B$ ) including cells with the morphology of protoplasmic astrocytes (Fig. $2 B$, arrowhead) (Bushong et al., 2002). The majority of O-EYFP ${ }^{+}$cells were $\mathrm{CC}^{+}$mature oligodendrocytes (Fig. 2C,F), in line with the observation that the majority of Olig ${ }^{+}$cells were $\mathrm{CC}^{+}{ }^{+}$(Fig. $1 E, F$ ). However, consistent with our finding that $\mathrm{GM} \mathrm{GFAP}^{+}$astrocytes

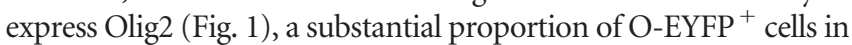
the adult spinal cord GM were protoplasmic astrocytes $(18 \pm 5.9 \%$ of total GM O-EYFP ${ }^{+}$cells were GFAP ${ }^{+}$) (Fig. 2C,G, arrowheads). In fact, the density of $\mathrm{O}-\mathrm{EYFP}^{+}$astroglia in gray matter was comparable to that of $\mathrm{O}-\mathrm{EYFP}^{+} \mathrm{NG}^{+} \mathrm{OPCs}(20 \pm 4$ $\mathrm{O}-\mathrm{EYFP}+\mathrm{GFAP}^{+} / \mathrm{mm}^{2}$ vs $24 \pm 3 \mathrm{O}-\mathrm{EYFP}^{+} \mathrm{NG} 2^{+} / \mathrm{mm}^{2}$ ) (Fig. $2 D, E, G, H)$. Recombination rates in $\mathrm{NG}_{2}{ }^{+}$OPCs were $42 \pm 14 \%$ and $43 \pm 10 \%$ in WM and GM of the adult spinal cord, respectively. Therefore, administration of tamoxifen to OCER mice labels and fate-maps GM GFAP ${ }^{+}$astrocytes as well as $\mathrm{NG} 2^{+}$ OPCs and $\mathrm{CC}^{+}{ }^{+}$oligodendroglia.

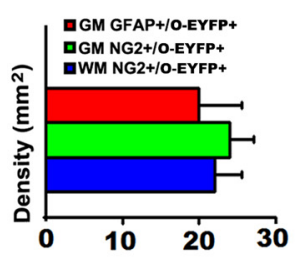

The density of $\mathrm{O}-\mathrm{EYFP}^{+} \mathrm{NG}^{+}$OPCs and $\mathrm{O}-\mathrm{EYFP}^{+} \mathrm{CCl}^{+}$oligodendrocytes in OCER mice changed reciprocally (Fig. $3 B-D)$, whereas O-EYFP ${ }^{+} \mathrm{GFAP}^{+}$astroglial density remained constant up to $180 \mathrm{~d}$ post-TM (Fig. 3E). With prolonged administration of BrdU in drinking water, beginning simultaneously with the first administration of tamoxifen (Fig. 3A), we found that, by $15 \mathrm{~d}$ post-TM, $\mathrm{O}-\mathrm{EYFP}^{+} \mathrm{NG}^{+}{ }^{+} \mathrm{OPC}$ constituted the majority of proliferating parenchymal cells $\left(\sim 90 \%\right.$ of total $\mathrm{BrdU}^{+}$cells) (Fig. $3 F$ ),

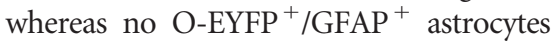
incorporated BrdU (Fig. 3F). BrdU administration was stopped at $15 \mathrm{~d}$ post-TM, and, at later time-points, numbers of $\mathrm{O}-\mathrm{EYFP}^{+} /$ $\mathrm{CCl}^{+} / \mathrm{BrdU}^{+}$oligodendrocytes progressively increased (Fig. $3 F, G$ ). This result was compatible with a precursor/product relationship between OPCs and oligodendroglia. From these BrdU labeling experiments in normal adult OCER mice, however, no $\mathrm{O}-\mathrm{EYFP}^{+} / \mathrm{GFAP}^{+} / \mathrm{BrdU}^{+}$astrocytes were found in the spinal cord (Fig. $3 F, G$ ) up to $180 \mathrm{~d}$ post-TM. These results strongly suggested that, in the normal adult spinal cord, OPCs do not generate astrocytes, and are restricted to the oligodendroglial lineage, and that GM astrocytes are postmitotic.

\section{OPCs remain restricted to the}

oligodendroglial lineage during EAE Using BrdU labeling and marker immunostaining (e.g., for Olig2), previous studies proposed that OPCs generate reactive astrocytes after EAE or spinal cord trauma (Cassiani-Ingoni et al., 2006; Magnus et al., 2007, 2008). To assess the plasticity of OPCs in EAE, we analyzed the progenies of OPCs in OCER mice by inducible Cre-LoxP fate mapping. OCER mice were immunized with MOG-peptide (Soulika et al., 2009) at $35 \mathrm{~d}$ post-TM to maximally diminish the effects of antecedent TM on severity of EAE (Bebo et al., 2009). When EAE clinical symptoms first appeared (generally 12 14 d post-MOG-peptide immunization), there was a sharp increase in proliferation of $\mathrm{Ibal}^{+}$microglia/ macrophages (data not shown). By D21 post-MOG peptide immunization, when EAE clinical deficits were most severe (Soulika et al., 2009), pulse (2 h) EdU labeling demonstrated a fivefold increase in OPC proliferation over levels in controls $(5.1 \pm 1.2 \%$ in CFA controls vs $25.4 \pm 6.7 \%$ in EAE, of NG2 ${ }^{+}$OPCs were $\mathrm{EdU}^{+}$(Fig. $4 A$, arrowheads and higher-magnification channels), respectively, $p<0.01$ ). Consistent with this rise in OPC proliferation, the number of $\mathrm{O}-\mathrm{EYFP}^{+} / \mathrm{NG}{ }^{+} \mathrm{OPC}$ increased in both WM (Fig. $4 B$ ) and GM (Fig. $4 C$ ), and their processes became retracted (Fig. $4 B$, boxed area and insets $B 1, B 2$ ), a morphological feature characteristic of activated OPCs, compared with those in normal tissues (Fig. $4 B$, insets $B 3, B 4$ ). Some OPCs were distributed in clusters around and/or within areas of dense accumulations of DAPI-nuclear stained inflammatory cells (Fig. $4 \mathrm{~B}$, dotted line area). The densities of $\mathrm{WM} \mathrm{O}^{-\mathrm{EYFP}^{+}} \mathrm{NG}^{+}{ }^{+} \mathrm{OPCs}$ in EAE spinal cord were $\sim 3.5$-fold and 2.5-fold higher than in CFA control spinal cord at D21 and D56 post-MOG peptide immuniza- 
tion, respectively (Fig. $4 B$, right), whereas in GM, their densities were $\sim 2.4$-fold and 2.7-fold higher than in the CFA controls, respectively (Fig. $4 C$, right). Interestingly, the density O-EYFP ${ }^{+} / \mathrm{CCl}^{+}$mature oligodendrocytes was also significantly higher in EAE than CFA control spinal cord at D56 post-MOG peptide immunization $(68 \%$ increase in WM, $p=0.012$; $54 \%$ increase in GM, $p=0.043$ ) (Fig. $4 E, F)$, although these differences did not reach significance at D21 post-MOG peptide immunization (Fig. $4 F$, left). Virtually all O-EYFP ${ }^{+}$cells in WM were colabeled with Sox10, a pan-oligodendroglial lineage marker (Fig. 4D). Thus, during EAE, spinal cord $\mathrm{O}-\mathrm{EYFP}^{+} \mathrm{NG}^{+}$OPCs increased in number and proliferative rate, and generated increased numbers of oligodendroglia. In contrast, while some $\mathrm{O}-\mathrm{EYFP}^{+} \mathrm{GFAP}^{+}$ astrocytes (Fig. 4G) in the GM of OCER mice became reactive, as demonstrated by their expression of vimentin (Fig. $4 \mathrm{H}$ ), the number of these O-EYFP ${ }^{+}$astroglia remained at control levels throughout the period of observation $\left(\mathrm{O}-\mathrm{EYFP}^{+} \mathrm{GFAP}^{+}\right.$cells $/ \mathrm{mm}^{2}, 23 \pm 3$ in CFA Vs $25 \pm 4$ in MOG at D56). At late time points (e.g., D56 postMOG peptide immunization), there were rare $\mathrm{O}-\mathrm{EYFP}^{+} / \mathrm{GFAP}^{+}$astrocytes in $\mathrm{WM}$ $\left(\sim 2.5 \%\right.$ of total WM O-EYFP ${ }^{+}$cells), but most of these cells were distributed at the junction between GM and WM (data not shown), and none of these cells incorporated BrdU under our BrdU paradigm (Fig. 4I).

If OPCs did contribute to the formation of astroglia during EAE, and if OPCs were labeled with BrdU before MOG-peptide immunization (Fig. 4I), then O-EYFP ${ }^{+} /$ $\mathrm{BrdU}^{+}$astrocytes would be expected to accumulate in spinal cord during subsequent EAE. To test this prediction, we administered BrdU in drinking water $(1 \mathrm{mg} / \mathrm{ml})$ for 15 consecutive days before EAE induction (Fig. 4I). We observed that $25 \pm 5.6 \%$ of $\mathrm{O}-\mathrm{EYFP}^{+} / \mathrm{NG}^{+} \mathrm{OPCs}$ (OPCs in WM and $\mathrm{GM}$ pooled) were $\mathrm{BrdU}^{+}$on the day of MOG peptide administration. But whereas O-EYFP ${ }^{+} / \mathrm{BrdU}^{+}$OPCs (Fig. 4J, arrows and higher-magnification image; $4 K$, boxed area 1 ) and ${\mathrm{O}-\mathrm{EYFP}^{+} /}^{+}$ $\mathrm{BrdU}^{+}$mature oligodendrocytes (Fig. $4 \mathrm{~J}$, arrowheads and highermagnification image; $4 K$, arrowheads) remained abundant later in the course of EAE, few O-EYFP ${ }^{+}$cells with characteristic morphology of GM protoplasmic astrocytes (Bushong et al., 2002) (Fig. $4 \mathrm{~J}$, wavy arrows and higher-magnification image) $(\sim 0.1 \%$, 1 of $865 \mathrm{EYFP}^{+}$astrocytes quantified from $4 \mathrm{EAE}$ mice) were $\mathrm{BrdU}^{+}$ in pooled WM and GM from these mice. Collectively, we concluded that OPCs did not contribute significantly to astrogenesis during EAE.

Characterization and genetic labeling of ependymal cells in spinal cord

We then addressed the plasticity of ependymal cells in EAE, and their contribution to astrogenesis. We began by phenotypically

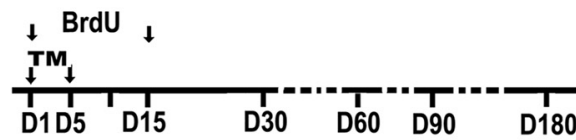

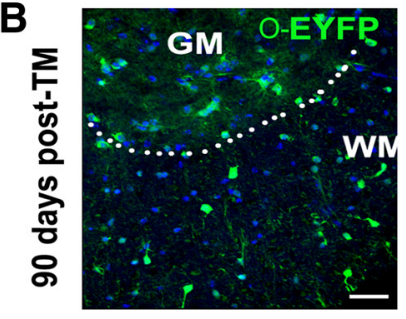

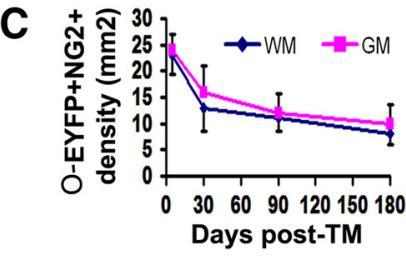

E
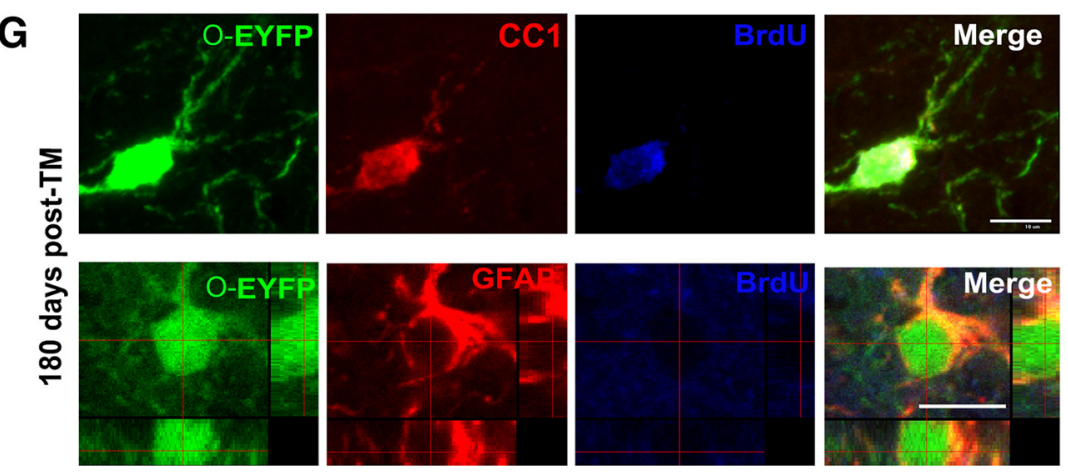

Figure 3. Normal fates of Olig2-expressing OPCs and GM astroglia. $\boldsymbol{A}$, Experimental design for $\boldsymbol{B}-\boldsymbol{G}$. $\boldsymbol{B}$, Confocal images from spinal cord of OCER mice at $90 \mathrm{~d}$ post-TM showing extensive colocalization of EYFP and CC1, a marker for mature oligodendrocytes. $\boldsymbol{C}-\boldsymbol{E}$, Quantification of 0 -EYFP ${ }^{+} / \mathrm{NG2}{ }^{+} \mathrm{OPCS}, 0$-EYFP ${ }^{+} / \mathrm{CC}^{+}{ }^{+}$mature oligodendrocytes, and 0 -EYFP ${ }^{+} / \mathrm{GFAP}^{+}$astrocytes in $\mathrm{BrdU}^{+}$cells in OCER spinal cord at different times post-TM. G, Confocal images of OCER spinal cord at $180 \mathrm{~d}$ post-TM, showing the presence of 0 -EYFP ${ }^{+} / \mathrm{CC}^{+} / \mathrm{BrdU}^{+}$mature oligodendrocytes (top) and absence of 0 -EYFP ${ }^{+} / \mathrm{GFAP}^{+} / \mathrm{BrdU}^{+}$astrocytes (bottom, orthogonal views) following $15 \mathrm{~d}$ of $\operatorname{BrdU}$ administration $(\boldsymbol{A})$. Scale bars: $\boldsymbol{B}, 50 \mu \mathrm{m} ; \boldsymbol{G}, 10 \mu \mathrm{m}$. characterizing and genetically labeling spinal cord ependyma. Like forebrain ependymal cells (Mirzadeh et al., 2008), ependymal cells surrounding the spinal cord central canal uniformly expressed immunoreactive vimentin (Fig. 5A). Their vimentin ${ }^{+}$ processes extended to the edges of dorsal (Fig. $5 A$ left, arrows) and ventral white matter (Fig. $5 A$ right, arrowheads), whereas their lateral processes were much shorter (Fig. $5 A$ ). Immunoreactive nestin expression was preferentially restricted to dorsal and ventral ependyma (Fig. $5 B$ left, arrowheads), as reported previously (Hamilton et al., 2009). However, in Nestin-GFP transgenic mice, all spinal cord ependymal cells were $\mathrm{GFP}^{+}$(Fig. 5B, right). In contrast to prior reports (Takahashi et al., 2003; Hamilton et al., 2009), we found that spinal cord ependymal cells were not $\mathrm{GFAP}^{+}$, nor did they express GFP in normal (Fig. 5C, left) or EAE 

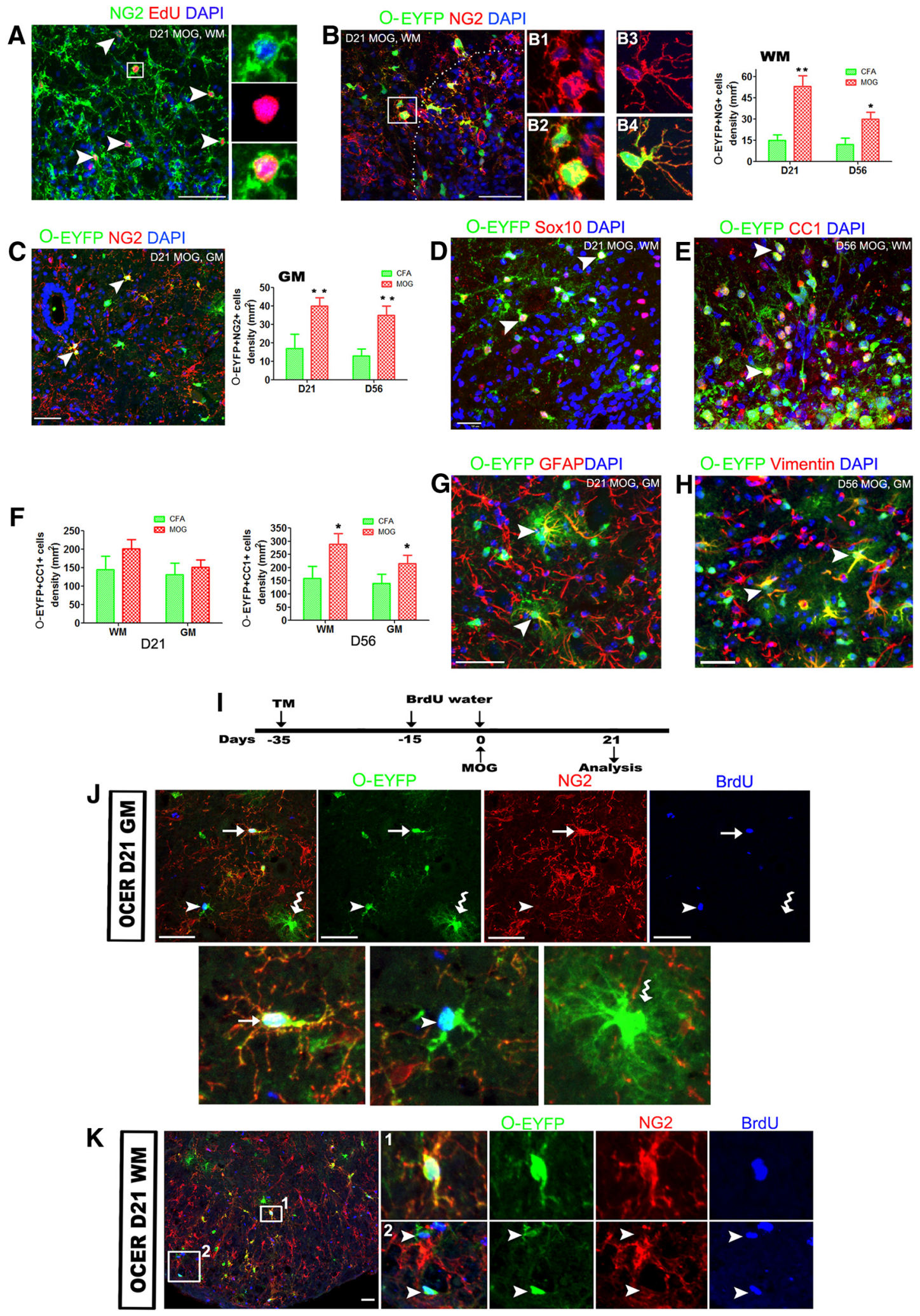

Figure 4. OPCs predominantly produce oligodendroglial lineage cells during EAE. $A, N G{ }^{+}$cell proliferation is brisk during EAE(2h EdU pulse labeling on D21 post-MOG-peptide immunization). Boxed area is shown at highermagnification on theright. B, C, Images (D21 post-MOG-peptideimmunization) and quantifications of0-EYFP ${ }^{+} \mathrm{NG2}{ }^{+}$OPCsin WMand GM, respectively. Dotted areain Bindicates inflammatoryinfiltration, as revealed by dense DAPI staining. Boxed area in $\boldsymbol{B}$ is shown at higher magnification in $\boldsymbol{B 1}, \boldsymbol{B} 2 . \boldsymbol{B} 3$ and $\boldsymbol{B} 4$ show 0 -EYFP ${ }^{+} \mathrm{NG2}{ }^{+} \mathrm{OPCs}$ in normal spinal cord, with fine, long processes. $\boldsymbol{D}$, Image (D21, WM) showing almost all of the 0 -EYFP ${ }^{+}$cells express the pan-oligodendroglial marker Sox10. E, Image (D56, WM) showing colabeling of 0-EYFP and mature oligodendrocytes marker, $C \mathrm{C} 1 . F_{\text {, Density of } 0 \text {-EYFP }}{ }^{+} \mathrm{CC} 1^{+}$mature oligodendrocytes on D21 (left) and D56 (right) post-MOG-peptide immunization in WM and GM. G, Confocal image (D21,GM) of O-EYFP and GFAP immunostaining.H, O-EYFP ${ }^{+}$cells with astrocyticmorphology in GM express vimentin, a marker

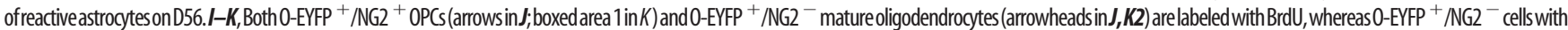
characteristic bushy astrocytic morphology (wavy arrows in J) are negative for BrdU on D21 post-MOG-peptide immunization under our BrdU labeling paradigm (I). Cells marked with arrow, arrowheads, and wavy arrow in the top of $J$, respectively, are shown at higher magnification in the bottom. Arrowheads in $A-H$ are examples of double-positive cells. Scale bars, $50 \mu \mathrm{m}$. 


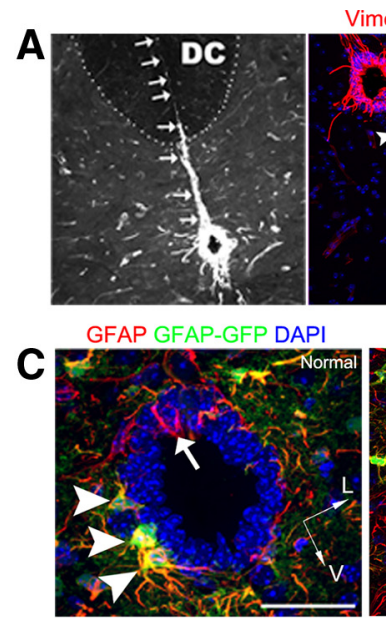

Vimentin DAPI
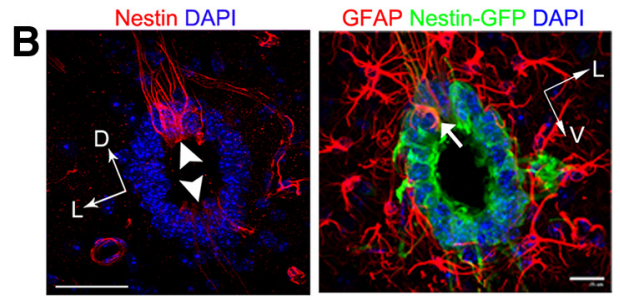

GFAP GFAP-GFP DAPI

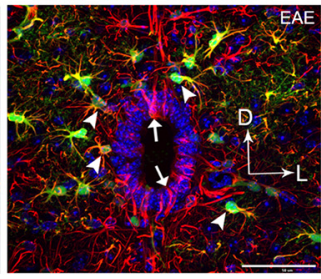

D
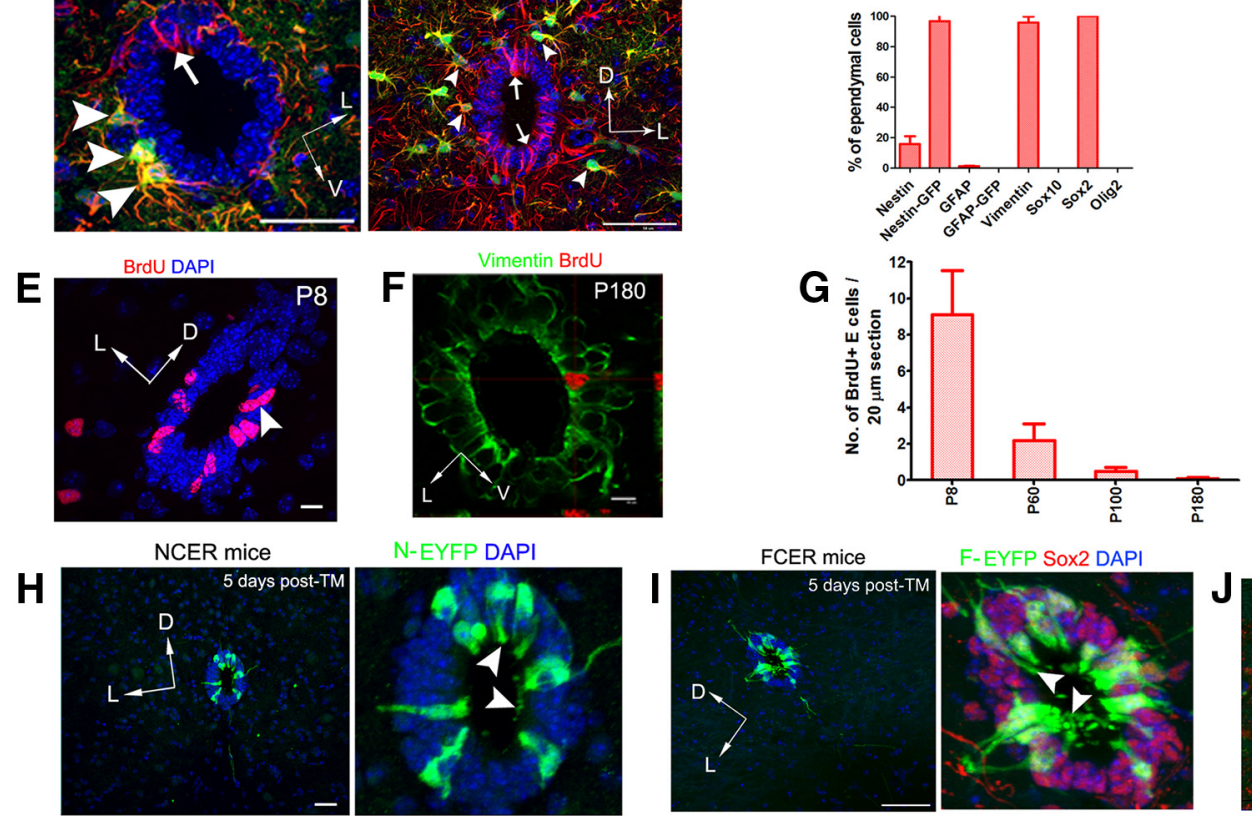

N-EYFP DAPI
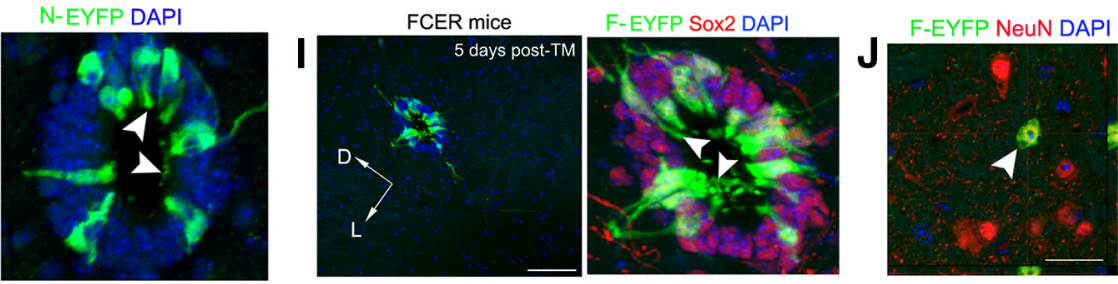

Figure 5. Characterization and genetic labeling of spinal cord ependymal cells. $A$, Ependymal cells extend Vimentin ${ }^{+}$processes to dorsal column (arrows on the left) and ventral WM (arrowheads on the right). $\boldsymbol{B}$, Nestin expression is restricted to dorsal and ventral parts of ependymal layers (left, arrowheads); however, reporter GFP is expressed uniformly in the ependymal cells in Nestin-GFP mice (right). Arrow indicates GFAP ${ }^{+}$processes in the ependymal layers. C, Ependymal cells do not express GFAP in either normal (left) or EAE (right) mice, as visualized in GFAP-GFP mice, although GFAP ${ }^{+}$processes are present in spaces between ependymal cells (arrows). Note that GFAP-GFP ${ }^{+}$cells (arrowheads) are close to the ependymal layer; however, ependymal cells never express GFAP-GFP. D, Percentage of ependymal cells that express different molecular markers. $\boldsymbol{E}, \boldsymbol{F}$, Confocal images showing BrdU ${ }^{+}$ependymal cells in P8 and P180 spinal cord, respectively. Arrowhead in $\boldsymbol{E}$ points to the cleavage plane of ependymal cell division. $\boldsymbol{G}$, Histograms depicting proliferation dynamics of ependymal cells at different ages. BrdU paradigms: P8, 3 injections (8h apart, $100 \mu \mathrm{g} / \mathrm{g}$ body weight) during P6-P7, analysis on P8; P60, BrdU drinking water (1 $\mathrm{mg} / \mathrm{ml}$ ) for $16 \mathrm{~d}$, analysis at P76; P100, BrdU drinking water (1 mg/ml) for 20 d, analysis at P120; P180, BrdU drinking water (1 mg/ml) for $25 \mathrm{~d}$, analysis at P205. H, I, At $5 \mathrm{~d}$ post-TM, ependymal cells are labeled with reporter EYFP in both Nestin-Cre-ERT2/Rosa-EYFP (NCER) $(\boldsymbol{H})$ and FoxJ1-Cre-ERT2/Rosa-EYFP (FCER) $(\boldsymbol{I})$ transgenic mice. The right panels in $\boldsymbol{H}$ and $\boldsymbol{I}$ are higher-magnification images of their left panels, respectively. Arrowheads in $\boldsymbol{H}$ and $\boldsymbol{I}$ point to EYFP ${ }^{+}$apical process of EYFP ${ }^{+}$ependymal cells. $\boldsymbol{J}$, In both FCER and NCER lines, EYFP reporter-positive neurons (arrowhead) with NeuN immunoreactivity are observed in GM, reflecting the ectopic transgene expression. D, Dorsal; V, ventral; L, lateral. Scale bars: $A-C, I, 50 \mu \mathrm{m} ; \boldsymbol{H}, 25 \mu \mathrm{m} ; \boldsymbol{E}, \boldsymbol{F}, \boldsymbol{J}, 10 \mu \mathrm{m}$.

(Fig. 5C, right) GFAP-GFP transgenic mice, though GFAP-GFP ${ }^{+}$ cells were in close proximity to ependyma (Fig. 5C, arrowheads), and $\mathrm{GFAP}^{+}$processes were inserted between ependymal cells in both normal (Fig. 5B right, arrow; Fig. 5Cleft, arrow) and EAE spinal cord (Fig. $5 C$ right, arrows), a relationship similar to that described between $\mathrm{GFAP}^{+}$cells and ependyma in the forebrain subventricular zone (Mirzadeh et al., 2008). Additionally, ependymal cells in adult spinal cord uniformly expressed the neural stem cells marker, Sox2 (Fig. 5D) (Meletis et al., 2008), and were negative for Olig2 and for the oligodendroglial lineage marker, Sox10 (Fig. 5D). To evaluate the proliferative potential of normal spinal cord ependymal cells, we administered BrdU to mice at various ages, and observed a progressive decline in the BrU labeling index (Fig. 5E-G). Though ependymal cell mitotic indices were robust in the early postnatal period $(\sim 9$ $\mathrm{BrdU}^{+}$ependymal cells/20 $\mu \mathrm{m}$ section at P8), by P180, ependymal cells rarely proliferated $\left(0.1 \mathrm{BrdU}^{+}\right.$ependymal cells $/ 20 \mu \mathrm{m}$ section $)$ (Fig. 5G).

Two groups of double transgenic mice, Nestin-Cre-ER ${ }^{\mathrm{T} 2} /$ Rosa-loxpP-STOP-loxP-EYFP (NCER) and FoxJ1-Cre-ER ${ }^{\mathrm{T} 2} /$ Rosa-loxP-STOP-loxP-EYFP (FCER), with Rosa-loxP-STOP-
loxP-EYFP recombination induced by a $5 \mathrm{~d}$ tamoxifen paradigm (Guo et al., 2010) and analysis at day 5 after last tamoxifen injection ( $5 \mathrm{~d}$ post-TM), were used to genetically label ependymal cells. EYFP was expressed predominantly in ependymal cells encircling the central canal in both NCER and FCER mice (Fig. $5 H, I)$. Most of these ependymal cells extended $\mathrm{EYFP}^{+}$apical processes into the lumen of central canal (Fig. $5 \mathrm{H}, \mathrm{I}$, arrowheads), a characteristic of ciliated ependymal cells. The recombination rates among ependymal cells were $12 \%$ and $29 \%$ in NCER and FCER spinal cord, respectively. Rare $\mathrm{EYFP}^{+}$cells with neuronal morphology that expressed NeuN (Fig. 5J, arrowhead) were present in the gray matter of adult FCER and NCER spinal cord, presumably reflecting ectopic expression of the Nestin and FoxJ1 promoters in occasional neurons in these transgenic lines.

\section{Responses of spinal ependymal cells in EAE injury}

Using $2 \mathrm{~h}$ EdU pulses delivered at various time points during EAE, we found that the number of proliferating cells in spinal cord WM and GM peaked at D21 and D15 post-MOG peptide during EAE injury, respectively (Fig. 6A). Therefore, treatment 


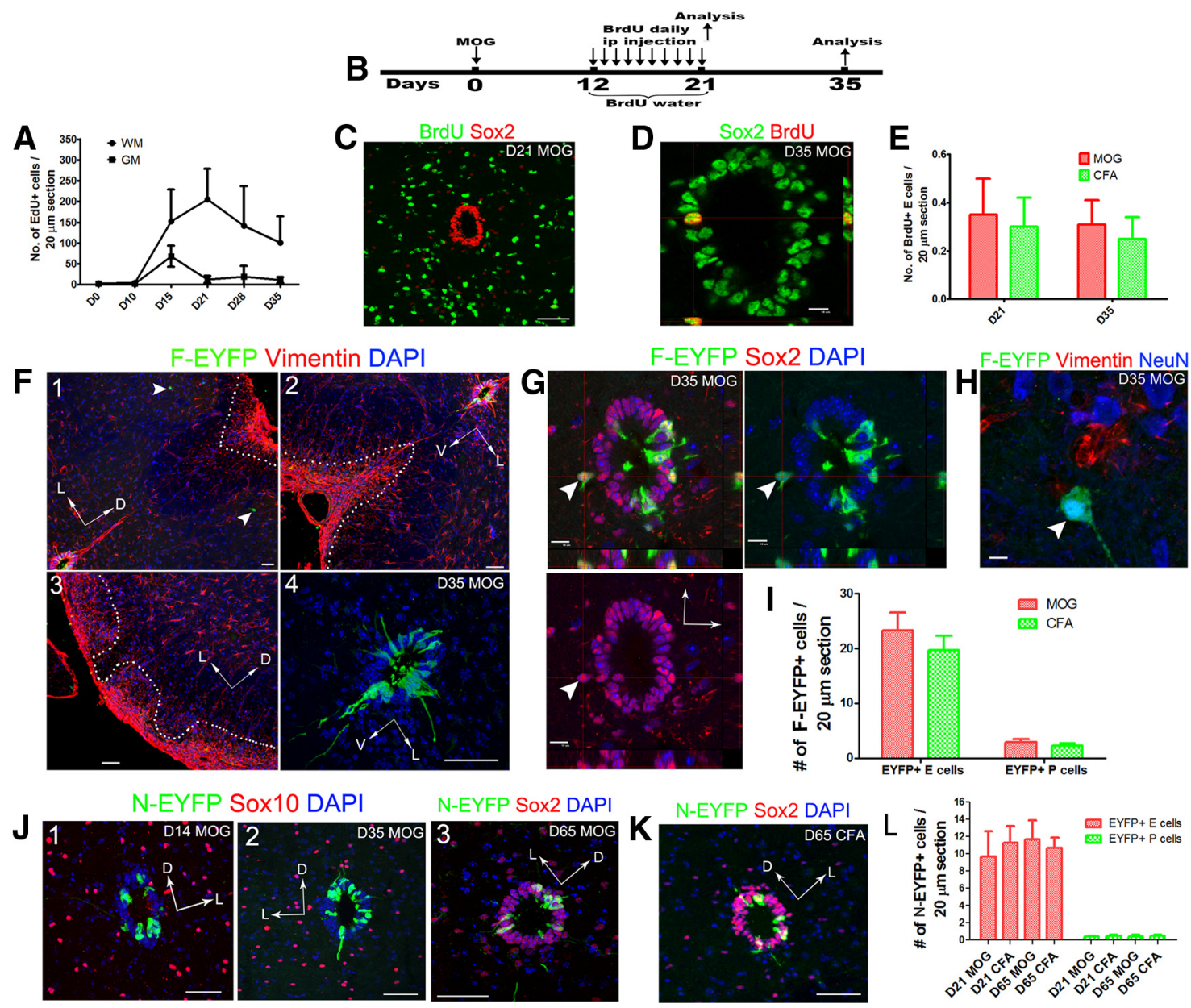

Figure 6. Responses of spinal cord ependymal cell during EAE. $A$, Number of EdU ${ }^{+}$cells in GM and WM per section at different days post-MOG-peptide immunization. $\boldsymbol{B}$, Experimental design for

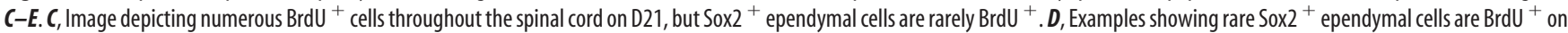
D35. E, Quantification of BrdU ${ }^{+}$ependymal cells per section in MOG and CFA spinal cords on D21 and D35, respectively. $F$, F-EYFP + ependymal cells (F4) in FCER mice do not generate progenies that migrate to dorsal $\left(\boldsymbol{F 1}\right.$ ), ventral $(\boldsymbol{F 2})$, and lateral $(\boldsymbol{F 3})$ regions where densely Vimentin ${ }^{+}$, glial scars (dotted area) are present, on D35 post-M0G. Arrowheads in $\boldsymbol{F 1}$ point to F-EYFP ${ }^{+} /$vimentin $^{-}$ neurons, as depicted in $\boldsymbol{H}$ with triple immunostaining of EYFP, Vimentin and NeuN (arrowhead). $\boldsymbol{G}$, Orthogonal confocal images showing rare F-EYFP ${ }^{+} /$Sox2 $^{+}$cells in close proximity to Sox2 ${ }^{+}$ ependymal layers on D35. I, Histograms showing the frequency of F-EYFP ${ }^{+}$ependymal (E cells) and parenchymal (P cells) cells in FCER mice on D35. J, Representative images showing N-EYFP ${ }^{+}$ ependymal cells in NCER mice do not generate Sox10 ${ }^{+}$or Sox2 ${ }^{+}$parenchymal cells on D14 (J1), D35 (J2), or D65 (J3) post-M0G spinal cords. $\boldsymbol{K}$, N-EYFP and Sox2 double-staining on D65 in a CFA control, a pattern similar to J. L, Quantification of frequency of N-EYFP ${ }^{+}$ependymal (E cells) and parenchymal (P cells) cells on D21 and D65. D, dorsal; V, ventral. Scale bars: $\boldsymbol{C}, \boldsymbol{F}, \boldsymbol{J}, \boldsymbol{K}, 50 \mu \mathrm{m} ; \mathbf{D}, \mathbf{G}$, H, $10 \mu \mathrm{m}$.

of EAE mice with BrdU administered both in drinking water and by daily intraperitoneal injection daily from D12 to D21 postMOG-peptide immunization (Fig. 6B) yielded numerous $\mathrm{BrdU}^{+}$cells throughout spinal cord, including in GM in close proximity to the central canal (Fig. 6C). However, $\mathrm{BrdU}^{+}$ ependymal cells (Fig. 6D) were rare in the EAE mice, and did not differ in their number from age-matched CFA controls $(0.35 /$ section in EAE vs 0.30 in CFA at D21;0.31/section in EAE vs 0.25 in CFA at D35 immunization, $p=0.87$ ) (Fig. $6 E$ ). These findings indicated that ependymal cell proliferation was not enhanced during EAE.

To determine whether ependymal cells produced progenies that migrated to areas of inflammation and astrogliosis during EAE, we sought reporter-positive cells in ependymal, gray, and white matter areas at various time points after TM administration and subsequent MOG peptide immunization in FCER mice. Very rare $\mathrm{F}_{-\mathrm{EYFP}}{ }^{+}$cells were noticed in transit from ependyma to dorsal (Fig. 6F1, dotted area), ventral (Fig. 6F2, dotted area) or lateral (Fig. $6 \mathrm{F3}$, dotted area) regions, where the accumulation of vimentin $^{+}$astroglia and $\mathrm{DAPI}^{+}$inflamed cells were ob- served even at lower-magnification images (Fig. $6 F$ ). Although $\mathrm{F} \mathrm{EYFP}^{+} / \mathrm{Sox}^{+}$cells were present in close proximity to ependyma (Fig. 6G, arrowheads), and F-EYFP ${ }^{+} / \mathrm{NeuN}^{+} / \mathrm{Vi}$ mentin ${ }^{-}$cells were present in GM (Fig. 6F1, arrowheads, $H$ ), these cells were rare and comparable in frequency in EAE and control spinal cords (Figs. 6I), indicating that their presence was independent of EAE injury. Consistent with the unaltered proliferative rate of spinal cord ependyma during EAE (Fig. $6 C-E$ ), numbers of F-EYFP ${ }^{+}$ependymal cells (E cells) and F-EYFP ${ }^{+}$ parenchymal cells ( $\mathrm{P}$ cells) did not change, and remained equivalent in MOG-EAE and CFA control FCER mice (Fig. 6I). These data suggested that ependymal cells did not contribute to astrogliosis during EAE. We strengthened this conclusion by studies in NCER mice, in which ependymal cells were also labeled with N-EYFP upon TM treatment (Fig. 5H). Consistent with results from the FCER mice, N-EYFP ${ }^{+}$cells in the NCER mice did not migrate away from ependyma on D14 (Fig. 6J1), D35 (Fig. 6J2), or D65 (Fig. 6J3) post-MOG peptide, results similar to those in CFA controls (Fig. $6 \mathrm{~K}$ ). Moreover, the numbers of $\mathrm{N}^{-\mathrm{EYFP}^{+}}$ ependymal cells (E cells) and N-EYFP ${ }^{+}$parenchymal cells $(\mathrm{P}$ 


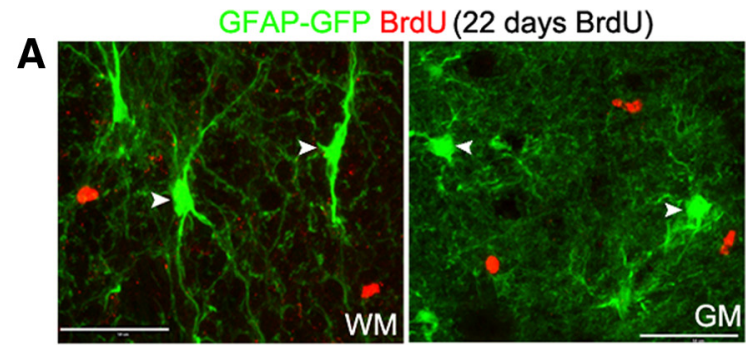

G-EYFP Nestin DAPI

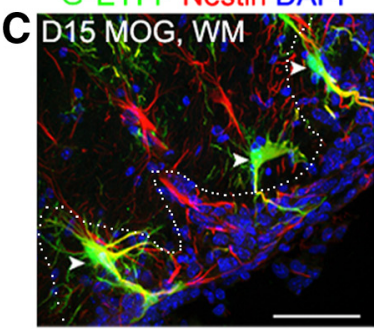

G-EYFP Vimentin DAPI

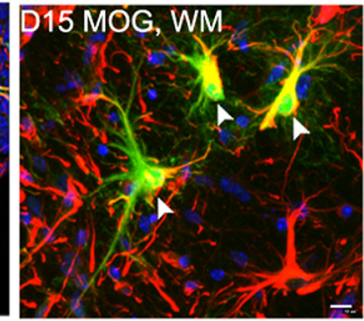

G-EYFP Vimentin DAPI

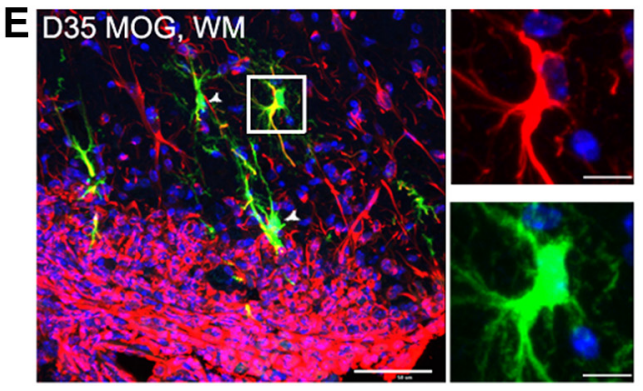

G

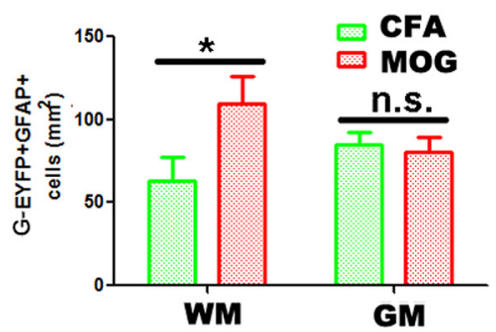

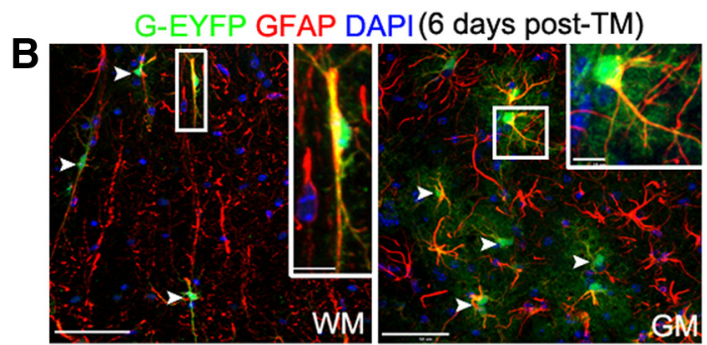
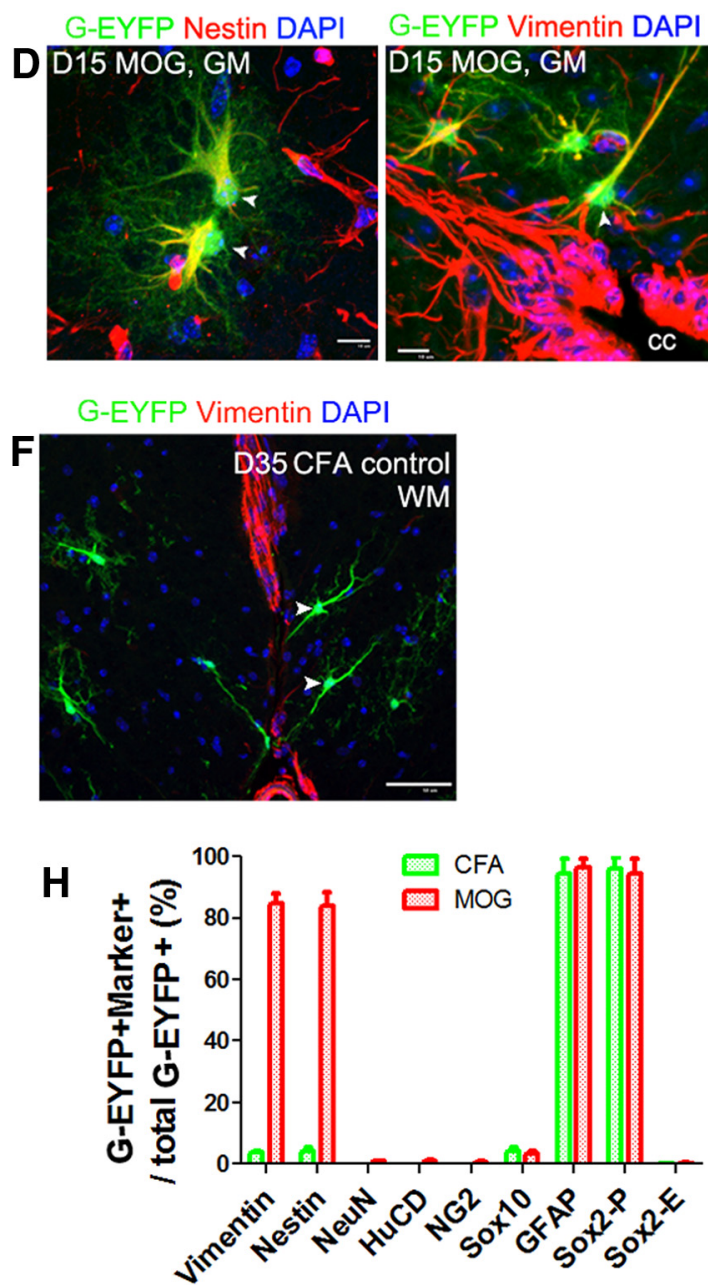

Figure 7. Reactive astrocytes are generated from resident quiescent astrocytes. A, Virtually no GFAP-GFP ${ }^{+}$cells (arrowheads) are positive for BrdU in either WM or GM in normal adult GFAP-GFP mice that received 22 consecutive days of BrdU labeling. B, Six days post-TM treatment of GCERmice, G-EYFP ${ }^{+} / \mathrm{GFAP}^{+}$cells (arrowheads) with typical astrocytic morphology are scattered throughout WM and GM. Boxed areas are shown at higher magnification as insets. $C, D$, By D15 post-MOG-peptide immunization, G-EYFP ${ }^{+}$astrocytes (arrowheads) have become activated in both WM ( $(\boldsymbol{C}$ and GM (D), as shown by expressions of immunoreactive Nestin (left) and Vimentin (right). Note that deep GM G-EYFP ${ }^{+}$astrocytes ( $\boldsymbol{D}$, right, arrowhead) in close proximity to central canal (cc) have also become Vimentin ${ }^{+}$at this time-point. $\boldsymbol{E}$, $\mathrm{G}_{\text {-EYFP }}{ }^{+}$Nimentin ${ }^{+}$-reactive astrocytes (arrowheads) in EAE spinal cord on D35 post-MOG. Boxed area is shown at higher magnification on the right. $\boldsymbol{F}$, G-EYFP ${ }^{+}$cells (arrowheads) do not express Vimentin

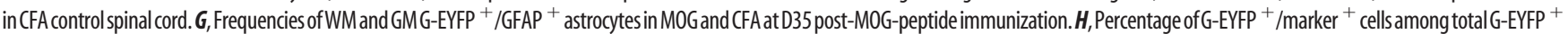
cells in spinal cord at D35 post-MOG-peptide immunization. Scale bars: A, B, D-F, C left panel, $50 \mu \mathrm{m} ;$ C right panel, D, $10 \mu \mathrm{m}$.

cells) were similar in MOG and CFA mice (Fig. 6L). Together, these data indicate that spinal cord ependymal cells do not contribute to astrogliosis, oligodendrogenesis and neurogenesis during EAE.

Resident quiescent astrocytes are the principal source for reactive astrogliosis in both $\mathrm{WM}$ and $\mathrm{GM}$ during $\mathrm{EAE}$

Our OCER fate-mapping data (Fig. 4) suggested that reactive astrocytes in spinal GM originated from resident postmitotic GM astrocytes. To strengthen and generalize this conclusion, we used GFAP-Cre-ER ${ }^{\mathrm{T} 2} /$ Rosa-loxP-STOP-loxP-EYFP (GCER) double transgenic mice to trace the fate of astrocytes in the EAE spinal cord. First, using normal adult GFAP-GFP mice to visualize astrocytes, and BrdU to label proliferating cells (22 consecutive days BrdU labeling in drinking water), we found that $0.05 \%$ and $0 \%$ of GFAP-GFP-positive astrocytes (3 mice, 6 sections/each animal analyzed) were $\mathrm{BrdU}^{+}$in spinal $\mathrm{WM}$ and $\mathrm{GM}$, respectively (Fig. 7A, arrowheads), suggesting that essentially all astrocytes in normal adult spinal cord are postmitotic.

Six days post-TM administration to adult GCER mice, $\mathrm{G}^{-E Y F P}{ }^{+}$astrocytes were scattered throughout both WM and GM (Fig. 7B, arrowheads). Most $\mathrm{GFAP}^{+} / \mathrm{G}^{-\mathrm{EYFP}^{+}}$cells in $\mathrm{WM}$ 

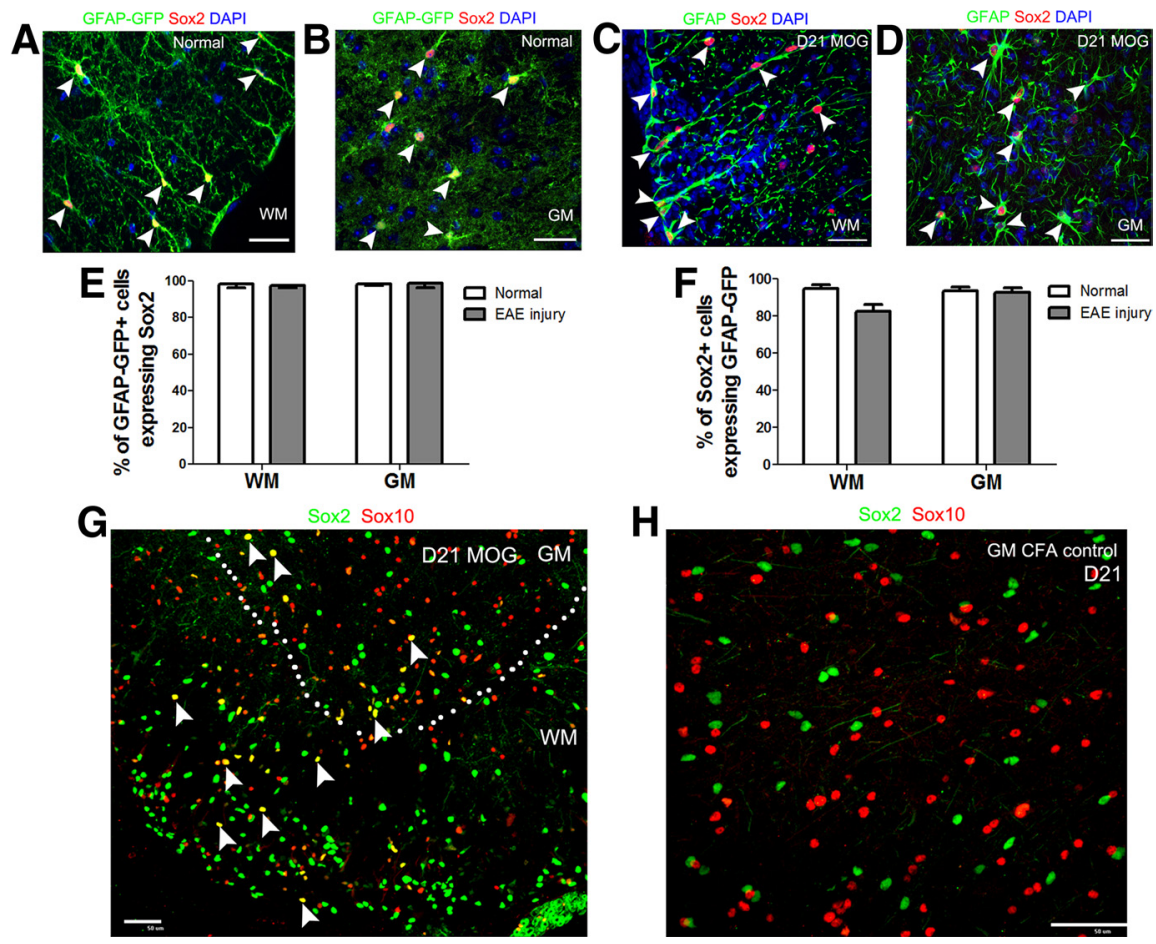

Figure 8. Sox2 is expressed by parenchymal astrocytes in adult normal and EAE spinal cord. $\boldsymbol{A}, \boldsymbol{B}$, Representative images showing colabeling of GFAP-GFP and Sox2 (arrowheads) in the spinal WM and GM of adult normal GFAP-GFP mice, respectively. $C$ D, Representative images of single optical slice showing colabeling of GFAP and Sox2 (arrowheads) in the WM and GM of D21 EAE

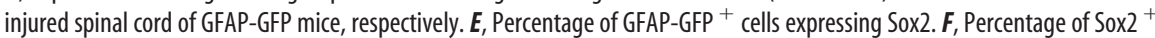
parenchymal cells expressing GFAP-GFP. G, Confocal image showing colabeling of Sox2 and Sox 10, a pan-oligodendroglial lineage cell marker in EAE spinal cord at D21. Note that some Sox2 ${ }^{+}$cells are Sox $10^{+}$(arrowheads), identifying them as oligodendroglial lineage cells. $\boldsymbol{H}$, Nonoverlapping Sox2 (green) and Sox10 (red) immunostaining in uninjured CFA control tissue. Blue in all images indicates $\mathrm{DAPI}^{+}$nuclei. Scale bars, $50 \mu \mathrm{m}$.

had an overall bipolar morphology, with one primary process extending toward the pial surface, another toward the central canal (Fig. 7B, left, and inset). Cells with this configuration in spinal cord are sometimes referred to as "radial astroglia" (Ban-

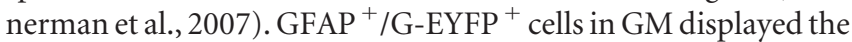
"bushy" processes typical of protoplasmic astrocytes (Fig. $7 B$, right, and inset). The densities of $\mathrm{GFAP}^{+} /{\mathrm{G}-\mathrm{EYFP}^{+}}^{+}$astrocytes were $\sim 63 / \mathrm{mm}^{2}$ and $85 / \mathrm{mm}^{2}$ in WM and GM, respectively. We used nuclear transcription factor Sox 2 immunoreactivity as an alternative to GFAP as a marker to identify spinal cord astrocytes (Fig. $8 A-F$ ), and found that $23.6 \%( \pm 1.6 \%$ ) and $24.3 \%$ $( \pm 4.7 \%)$ of Sox ${ }^{+}$astrocytes were labeled with G-EYFP ${ }^{+}$in the WM and GM of the normal GCER mice, respectively.

To provide direct evidence that $\mathrm{GFAP}^{+}$astrocytes resident in the normal spinal cord contribute to reactive astrogliosis, we immunized GCER mice with MOG peptide on 35 d post-TM. By day 15 post-MOG peptide immunization, when clinical symptoms were well established, the morphology of WM EYFP ${ }^{+}$astrocytes had changed from a bipolar to a hypertrophic, multipolar configuration (Fig. 7C, arrowheads, compared with Fig. 7B, left). These enlarged astroglia expressed immunoreactive Nestin (Fig. 7C, left) and Vimentin (Fig. $7 C$, right), characteristics of reactive astrocytes. Most of these G-EYFP ${ }^{+} / \mathrm{Nestin}^{+}$hypertrophic reactive astrocytes were distributed within or at the margins of inflammatory lesions (dotted area in Fig. 7C, left). In EAE spinal cord GM, G-EYFP ${ }^{+}$astrocytes displayed more numerous and thicker primary processes than in controls (compare Fig. 7B, right, with 7D), and had also become Nestin $^{+}$(Fig. 7D, left) and Vimentin ${ }^{+}$(Fig. 7D, right). Even deep in $\mathrm{GM}$, close to the central canal (cc), G-EYFP ${ }^{+}$astrocytes were
Vimentin $^{+}$(Fig. 7D, right, arrowhead), suggesting that the deep gray matter microenvironment was altered during EAE, as has previously been reported (Huizinga et al., 2008; Wu et al., 2008). The expression of Nestin and Vimentin by G-EYFP ${ }^{+}$astrocytes persisted at later time points (Fig. $7 E$, arrowheads and boxed area), indicating that astroglial activation during EAE is sustained. Virtually no G-EYFP ${ }^{+}$cells were positive for Vimentin in CFA GCER mice (Fig. 7F, arrowheads). Numbers of

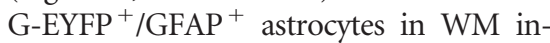
creased 0.75 -fold during EAE $\left(109 / \mathrm{mm}^{2}\right.$ EAE vs $65 / \mathrm{mm}^{2}$ in CFA controls, $p=$ 0.025) (Fig. 7G), whereas numbers of $\mathrm{G}^{-\mathrm{EYFP}^{+}} / \mathrm{GFAP}^{+}$astrocytes in $\mathrm{GM}$ did not change (Fig. 7G). Together, these data indicated that the hypertrophic, Vimentin ${ }^{+} / \mathrm{Nestin}^{+}$-reactive astrocytes that became prominent throughout spinal cord during EAE were direct descendents of resident quiescent $\mathrm{GFAP}^{+} / \mathrm{Nestin}^{-} / \mathrm{Vi}$ mentin $^{-}$astrocytes which resided in spinal cord before onset of EAE, and also suggested that astroglial hyperplasia contributed to astrogliosis in WM, but not in GM, which was subsequently addressed further by BrdU incorporation studies below.

Previous reports proposed that astrocytes gain multipotency after CNS traumatic injuries (Lang et al., 2004; Buffo et al., 2008). To determine the in vivo plasticity of reactive astrocytes during EAE,

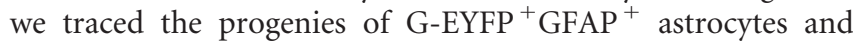
quantified the percentage of $\mathrm{G}-\mathrm{EYFP}^{+}$cells that were immunoreactive for different lineage markers. On day 35 post-MOG peptide immunization of GCER mice, $>95 \%$ of $\mathrm{G}^{-\mathrm{EYFP}^{+}}{ }^{+}$cells were $\mathrm{GFAP}^{+}$or Sox ${ }^{+}$(Fig. 7I), identifying them as astrocytic lineage members, and $\sim 80 \%$ of G-EYFP ${ }^{+}$cells were Vimentin ${ }^{+}$or Nestin $^{+}$-reactive astrocytes (Fig. $7 \mathrm{H}$ ). G-EYFP ${ }^{+}$cells that expressed neuronal lineage markers ( $\mathrm{HuCD}$ or NeuN) or oligodendroglial lineage markers (NG2 or CC1) were very rare (Fig. $7 H$ ). We concluded that reactive astrocytes in EAE remained restricted to the astroglial lineage.

\section{Different mechanisms underlie the formation of reactive} astrocytes in spinal white and gray matter during EAE injury Though previous studies provided substantive evidence for the proliferation of resident astrocytes after traumatic injury (Bush et al., 1999; Faulkner et al., 2004; Myer et al., 2006) and EAE (Voskuhl et al., 2009), whether astrogliosis in GM and WM in multiple sclerosis and EAE is due to both hyperplasia and hypertrophy or solely to hypertrophy remained unclear. To determine whether astrocytes were proliferative during EAE, BrdU was administered by combined intraperitoneal injection and addition to drinking water from D12 to D21 post-MOG peptide immunization, and spinal cord was analyzed at D35 postimmunization (Fig. 9A). We showed that almost all of parenchymal Sox $2^{+}$cells were GFAP-GFP ${ }^{+}$astrocytes in normal adult spinal cord (Fig. $8 A, B, E, F)$. However during EAE, although $\mathrm{GFAP}^{+}$astrocytes remained nuclear Sox 2 positive (Fig. $8 C, D$ ), some Sox ${ }^{+}$cells expressed transcription factor Sox10, a pan-oligodendroglial lin- 

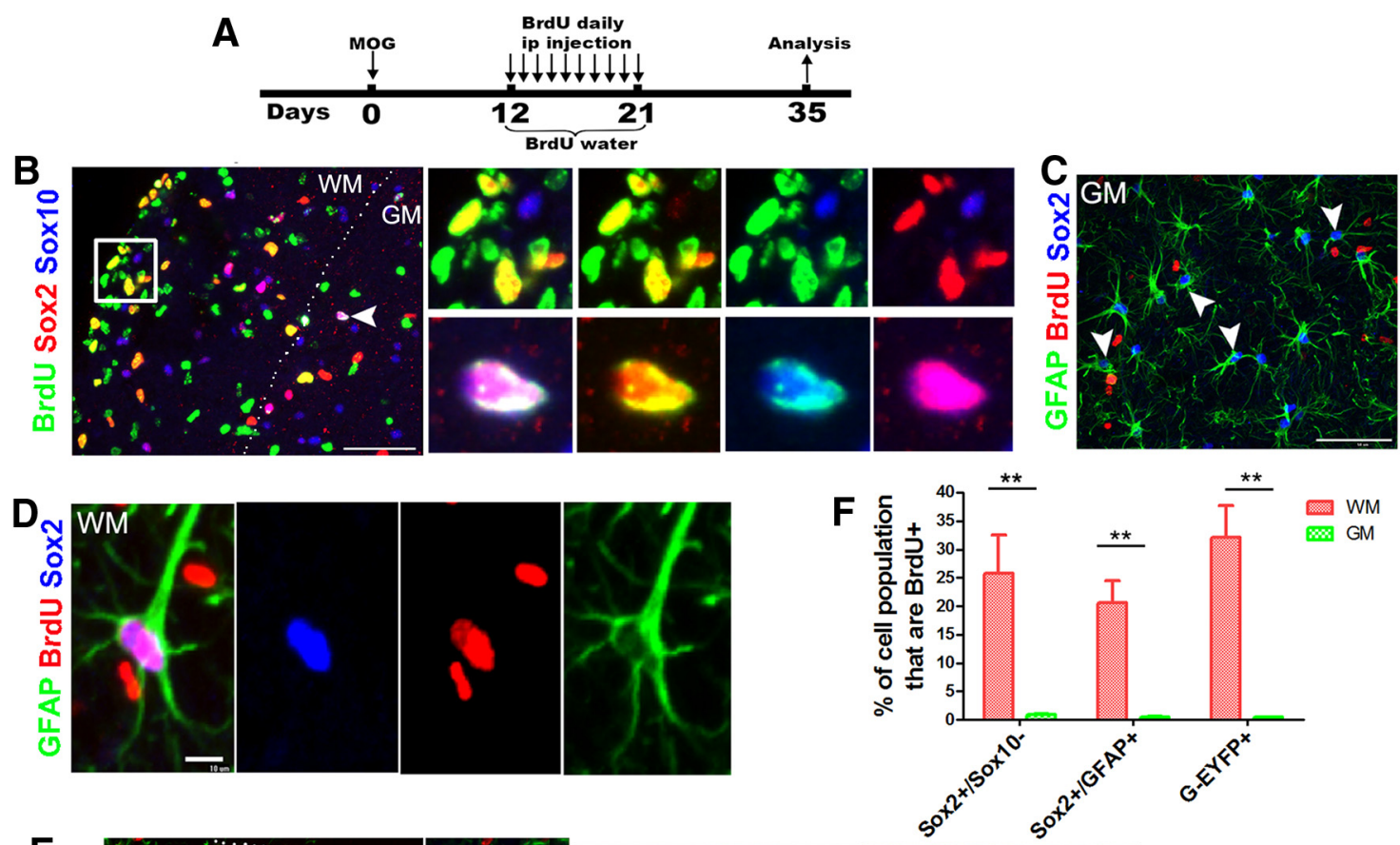

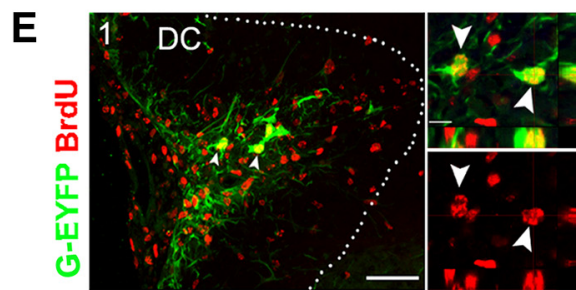

GFAP-GFP GFAP DAPI
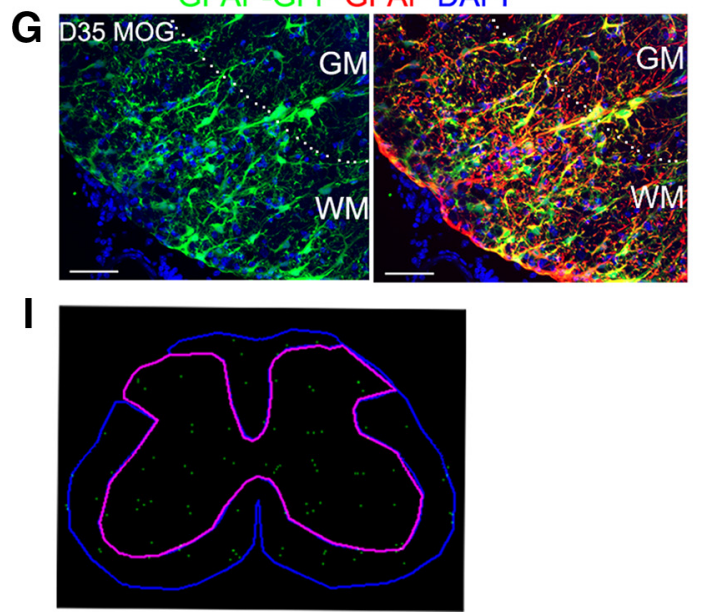
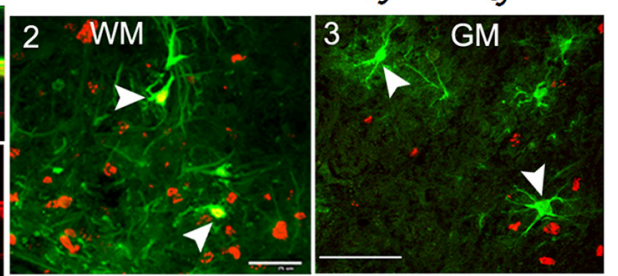

GFAP-GFP GFAP DAPI
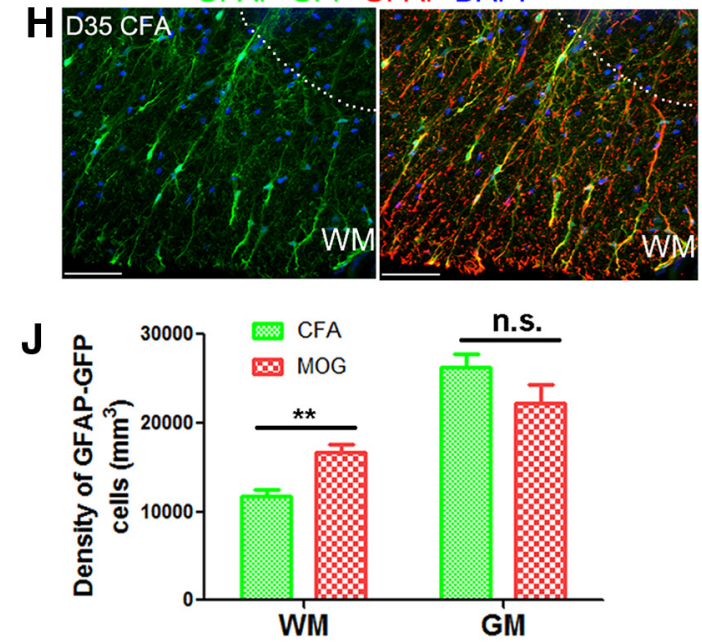

Figure 9. Hypertrophy and hyperplasia differentially contribute to formation of WM- and GM-reactive astrocytes. $\boldsymbol{A}$, Experimental designs for $\boldsymbol{B}-\boldsymbol{F}$. $\boldsymbol{B}$, Confocal images of BrdU, Sox2 and Sox 10

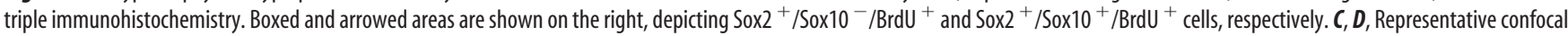

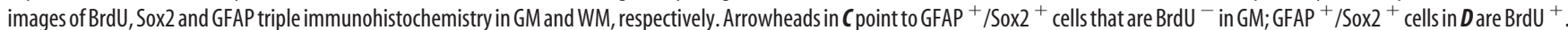
$\boldsymbol{E}, \mathbf{G}-\mathrm{EYFP}{ }^{+}$cells in dorsal column (DC) (E1, arrowheads and higher magnification) and ventral WM (E2, arrowheads) incorporate BrdU, whereas G-EYFP ${ }^{+}$cells (arrowheads) in GM (E3) are BrdU ${ }^{-}$ in GCER mice. $\boldsymbol{F}$, Histograms showing percentages of Sox $2^{+} / \mathrm{SOx}_{10}{ }^{-}$, Sox $2^{+} / \mathrm{GFAP}^{+}$, and G-EYFP ${ }^{+}$cells that are BrdU ${ }^{+}$in GCER mice on D35 post-MOG-peptide immunization. $\boldsymbol{G}, \boldsymbol{H}$, Representative confocal images depicting the overlapping of the GFAP-GFP reporter and GFAP immunoreactivity in EAE $(\boldsymbol{G})$ and CFA $(\boldsymbol{H})$ spinal cord of GFAP-GFP mice on D35. I, Schematic contours outlining the WM (blue) and GM (red) areas for stereological quantification of GFAP-GFP ${ }^{+}$cells.J, Density of GFAP-GFP ${ }^{+}$cells in WM and GM of GFAP-GFP mice on D35. n.s., Not significant. Scale bars, $50 \mu \mathrm{m}$ except $D, 10 \mu \mathrm{m}$.

eage cell marker (Fig. 8G, arrowheads), thus identifying them as oligodendroglial cells. Therefore, we double-immunostained for Sox10 and Sox2, and defined parenchymal astroglia in EAE spinal cord as those cells that were nuclear Sox $10^{-} /$Sox $2^{+}$. We found that $25.8 \%$ and $0.6 \%$ of Sox $10^{-} /$Sox $2^{+}$cells were BrdU positive in spinal WM and GM, respectively $(p<0.01)$ (Fig. $9 B, F)$. These results were confirmed by GFAP, Sox 2 and BrdU triple immunostaining, which showed that $20.6 \%$ and $0.26 \%$ of $\mathrm{GFAP}^{+} / \mathrm{Sox}^{+}$ cells had incorporated BrdU in WM and GM, respectively under this BrdU labeling paradigm (Fig. $9 C, D, F)(p<0.01)$. We also used GCER mice to label $\mathrm{GFAP}^{+}$quiescent astrocytes (Fig. $7 A, B)$ before induction of EAE, and assessed the proliferation of 


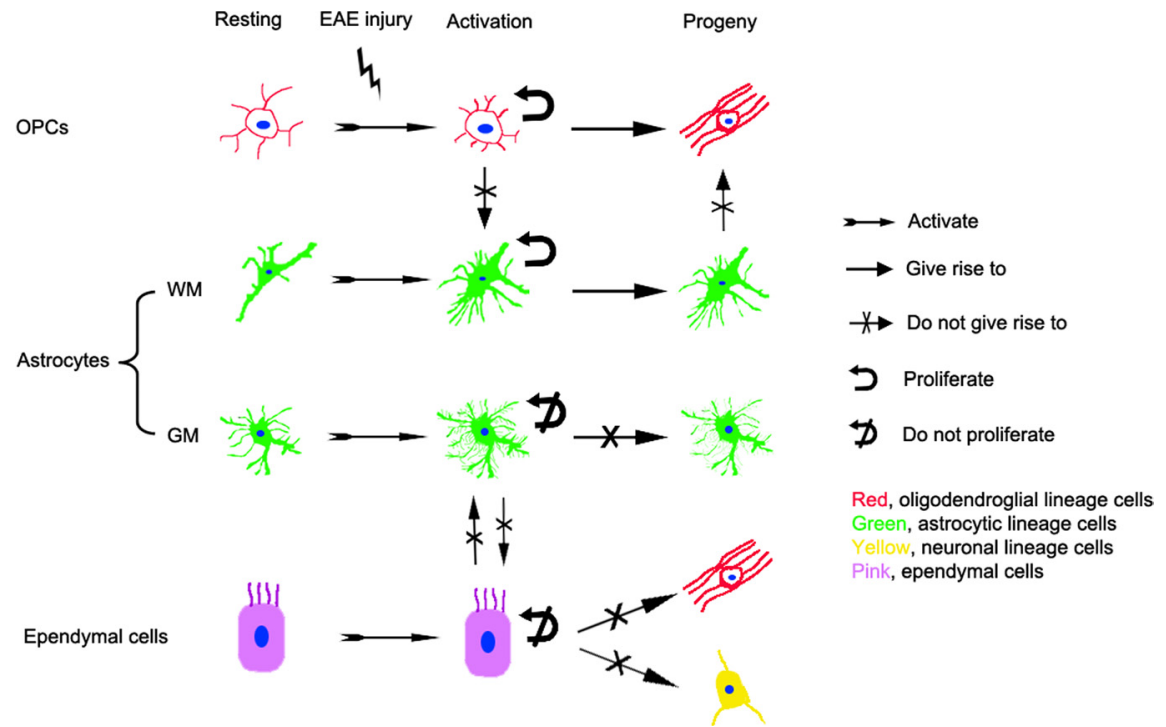

Figure 10. Schematic drawing of glial plasticity and their relationships during EAE. In $E A E$, (1) OPCs increase their proliferation, expand their population, and give rise to oligodendrocytes, but to few if any reactive astrocytes; (2) spinal cord normal WM Vimentin $^{-}$/Nestin ${ }^{-}$fibrous astrocytes become activated, as shown by expression of immunoreactive Vimentin and Nestin, and proliferate, but generate only astroglial lineage cells; (3) as in WM, GM Vimentin - /Nestin - protoplasmic astrocytes become Vimentin ${ }^{+} /$Nestin $^{+}$, but, unlike in WM, do not proliferate; and (4) ependymal cells become Nestin ${ }^{+}$, but do not increase their rate of proliferation, nor give rise to astroglia, neurons or oligodendrocytes.

$\mathrm{G}-\mathrm{EYFP}^{+}$astrocytes during EAE. Consistent with the Sox2/ Sox10 and Sox $2 /$ GFAP results (Fig. 9B-D), 32\% of G-EYFP ${ }^{+}$ astrocytes incorporated $\mathrm{BrdU}$ in spinal WM, including dorsal columns (Fig. 9E1) and ventral WM (Fig. 9E2). However, very few G-EYFP $^{+}$cells were BrdU positive in GM (0.15\%) (Fig. $9 E 3, F)(p<0.01)$. Together, these BrdU labeling data indicated that spinal cord WM astrocytes proliferate during EAE, whereas GM astrocytes become activated without proliferation.

Next, we used GFAP-GFP transgenic mice to identify GFAP ${ }^{+}$ astrocytes (Fig. $1 \mathrm{H}$ ), and found that there were more WM GFAP$\mathrm{GFP}^{+}$cells in spinal cord WM in EAE than in CFA control mice. In the EAE mice, most WM GFAP-GFP ${ }^{+}$astrocytes changed their morphology from typical bipolar to multipolar or irregular shapes (compare Fig. 9G with $9 H$ ). We used unbiased stereological counting to quantify GFAP-GFP ${ }^{+}$cells in spinal cord WM and GM (Fig. 9I). Results indicated that the density of GFAP$\mathrm{GFP}^{+}$cells was significantly higher in EAE than control spinal cord white matter $\left(16.6 \times 10^{3} / \mathrm{mm}^{3}\right.$ in MOG vs $11.7 \times 10^{3} / \mathrm{mm}^{3}$ in CFA, $p<0.001$ ) (Fig. 9J), whereas there was no significant difference in numbers of GFAP-GFP ${ }^{+}$cells between EAE and CFA controls in spinal cord gray matter (Fig. 9J), a result consistent with the previously mentioned BrdU labeling data (Fig. 9A$F$ ). Thus, in EAE, astrogliosis in spinal cord WM is a consequence of both hyperplasia and hypertrophy of WM astroglia, whereas astrogliosis in spinal cord in GM is a solely hypertrophic response of GM astroglia.

\section{Discussion}

Charcot, the first to integrate the clinical and pathological features of multiple sclerosis, believed that "hyperplasia of the reticulated fibers of the neuroglia constitutes the initial, fundamental fact, and necessary antecedent" of multiple sclerosis plaques (Charcot, 1877). Nearly 150 years later, the cellular origin(s) of reactive astroglia in this and other CNS disorders remain elusive (Robel et al., 2011). In the present study, we used genetic fate mapping, thymidine analog birth-dating, and nonbiased stereo- logical analysis to address the origins of spinal cord-reactive astroglia in a murine EAE model of multiple sclerosis, and also provide a comprehensive view of macroglia plasticity in the inflamed spinal cord (Fig. 10).

\section{OPCs are not diverted from oligodendrogenesis to astrogenesis in EAE spinal cord}

Our first goal was to assess the extent to which OPCs give rise to reactive astroglia in EAE. OPCs are the predominant proliferating cell population in the adult CNS (Rivers et al., 2008). Their capacity to generate astroglia in vitro when cultured in appropriate media, and in vivo, after transplantation, has been well established. Genetic fate-mapping has shown OPCs to generate astroglia in the intact neonatal CNS (Zhu et al., 2008; Guo et al., 2009; Zhu et al., 2011). Additional observations interpreted as favoring an origin of reactive astroglia from OPCs in CNS injured conditions were focused on the oligodendroglial lineage transcription factor Olig2 (Buffo et al., 2005; Magnus et al., 2007, 2008). Hypertrophic astroglia express Olig2 in the spinal cord in EAE (Cassiani-Ingoni et al., 2006) and other CNS injury models (Magnus et al., 2007, 2008), and genetic fate-mapping using a knock-in Olig2-Cre-ER transgene showed labeling of astroglia with a recombination marker (Tatsumi et al., 2008). Arguing against such a lineage relationship between OPCs and reactive astroglia, however, fate-mapping with the transgene Pdgfra-Cre-ER ${ }^{\mathrm{T} 2}$ failed to label reactive astroglia in spinal cord demyelinative and neurodegenerative models (Kang et al., 2010; Tripathi et al., 2010; Zawadzka et al., 2010). As a first step toward resolving these apparently contradictory results, we demonstrated that not only oligodendroglial cells but also the majority of normal adult spinal cord gray matter protoplasmic astroglia, identified phenotypically and by fate-mapping with GFAP-Cre$\mathrm{ER}^{\mathrm{T} 2}$, express immunoreactive Olig2 (Fig. 1), and hence would be expected to be fate-mapped by Olig2-Cre-ER (Fig. 4). In fact, virtually all the spinal cord OCER-fate-mapped astroglia in the EAE mice were in gray matter. Thus, Olig2-Cre-ER fatemapping, in the absence of additional data, could not be relied upon to evaluate a precursor/product relationship between OPCs and reactive astroglia in spinal cord gray matter, and the PdgfraCre-ER ${ }^{\mathrm{T} 2}$-based conclusion by Tripathi et al. (2010) that OPCs do not give rise to significant numbers of reactive astroglia in EAE is strengthened.

Another interesting observation of our study was that OPCs generated more $\mathrm{CCl}^{+}$mature oligodendrocytes in the chronic phase of EAE than in control spinal cord (Fig. 4E,F). Further studies are needed to determine whether these newly formed oligodendrocytes participate in spinal cord remyelination in EAE.

\section{Reactive astroglia are derived from cells that, in the normal spinal cord, are mitotically inactive}

What cells do give rise to reactive astroglia? To gain insight into the proliferative characteristics of the precursor pool from which reactive astroglia were derived during EAE, adult mice were sub- 
jected to prolonged BrdU administration before induction of EAE. OPCs became heavily BrdU-labeled during this period, whereas astroglia were rarely labeled (Figs. 3F, 7A). Reactive astroglia formed during EAE in these mice were also rarely $\mathrm{BrdU}^{+}$ (Fig. $4 J$ ), hence arguing against a significant contribution by OPCs to their genesis. These results supported the hypothesis that the Olig2 ${ }^{+}$astroglia and Olig2-Cre-ER fate-mapped astroglia previously reported, and confirmed in the present study, were derived from Olig ${ }^{+}$protoplasmic astroglia resident in adult gray matter (Chen et al., 2008), rather than from Olig2 ${ }^{+}$ OPCs.

\section{Spinal cord ependyma do not contribute to reactive astrogenesis in EAE}

Ependymal cells can both self-renew and generate multiple cell lineages under appropriate culture conditions (Meletis et al., 2008), and may also exhibit these stem cell-like properties during normal prenatal development and after CNS ischemia (Carlén et al., 2009). During EAE, we observed upregulation of immunoreactive nestin, a protein expressed by stem and progenitor cells, in spinal cord ependymal cells (data not shown) (Takahashi et al., 2003). Though DiI-labeling was reported to demonstrate derivation of astroglia and oligodendroglia (Brundin et al., 2003) and neurons (Danilov et al., 2006) from ependyma in the spinal cord during EAE, we consider the interpretation of that result not to be straightforward, because processes of $\mathrm{GFAP}^{+}$peri-ependymal astroglia (Fig. 5B,C), $\mathrm{NG}^{+}$processes of peri-ependymal OPCs (Horner et al., 2002) and $\mathrm{HuCD}^{+}$neurons (Marichal et al., 2009) are inserted between ependymal cells in spinal cord, and could also have taken up the DiI. Genetic fate-mapping with the inducible forkhead transcription factor-driven Cre transgene, FoxJ1Cre-ER ${ }^{\mathrm{T} 2}$, showed that ependyma in the incised adult spinal cord generate astroglia, and to a lesser extent, oligodendroglial lineage cells (Meletis et al., 2008; Barnabé-Heider et al., 2010). However, our fate-mapping with the same FoxJ1-Cre-ER ${ }^{\mathrm{T} 2}$ transgene failed to label substantial astroglia in EAE (Fig. 6). We used Sox2 to label both ependymal cells (Fig. 5D) and parenchymal astrocytes (Fig. $8 A, B, E, F$ ), and noted instances in which $\mathrm{F}_{-\mathrm{EYFP}}{ }^{+} / \mathrm{Sox} 2^{+}$cells were in close proximity to Sox $2^{+}$ependymal cells (Fig. 6G, arrowhead); these were rare, however, and similar in incidence in EAE and CFA controls (Fig. 6I). Furthermore, these $\mathrm{EYFP}^{+} / \mathrm{Sox} 2^{+}$cells did not accumulate over time in EAE (Fig. $6 L$ ). These observations suggest that ependymal cells contribute few, if any, astroglia to parenchymal peri-ependymal astrogenesis in EAE. Also arguing against a substantial role for ependymal cells in EAE astrogenesis, the mitotic index of ependymal cells in EAE spinal cord was maintained at the same very low level as in CFA control spinal cord (Fig. 6C-E), yet spinal cord ependymal cells were not depleted during EAE (Fig. 6F4,G,J). We concluded, therefore, that spinal cord ependymal cells contribute few if any reactive astroglia during EAE, and speculate that the discrepancy in FoxJ1-Cre-ER ${ }^{\mathrm{T} 2}$ ependymal fate-mapping in incised vs EAE spinal cord is attributable to the lesser disruption of the gray matter milieu in EAE than after physical injury.

A study of the spinal cord in a toxin-induced demyelination model found that reactive astroglia were generated from Fgfr3expressing cells (Zawadzka et al., 2010). However, Fgfr3 is expressed by both spinal cord astrocytes and ependymal cells (Young et al., 2010), and it is therefore not clear whether astrocytes, ependymal cells, or both contributed to this astrogliosis. Using GFAP-Cre-ER ${ }^{\mathrm{T} 2}$ to label astrocytes (Fig. 7) and FoxJ1 (or
Nestin)-Cre-ER ${ }^{\mathrm{T} 2}$ (Figs. 5, 6) to label ependymal cells, we have now shown that resident astrocytes, but not ependymal cells, contribute to reactive astrogliogenesis in CNS inflammatory demyelination.

\section{Reactive astroglia are generated from quiescent} vimentin-/nestin-astroglia in spinal cord white and gray matter Having failed to indict OPCs or ependymal cells as significant sources for nestin ${ }^{+} /$vimentin $^{+}$-reactive astroglia in EAE spinal cord, we evaluated the hypothesis that nestin ${ }^{-} /$vimentin ${ }^{+}$astroglia resident in the adult spinal cord generate reactive astroglia. In support of this hypothesis, reactive astroglia in EAE spinal cord gray and white matter were G-EYFP-labeled in GCER mice that had received tamoxifen before MOG peptide immunization (Fig. 7). BrdU incorporation studies showed the mitotic index of astroglia was very low in the normal adult spinal cord, and remained low in gray matter astroglia during EAE, but rose substantially in white matter astroglia (Fig. 9B-F). Consistent with these BrdU results, unbiased stereological analysis in GFAPGFP transgenic mice showed an increase in density of GFAP$\mathrm{GFP}^{+}$astroglia in spinal cord white but not gray matter during EAE (Fig. 9G-J).

While our data show that spinal cord-reactive astrogliosis involves astroglial proliferation in white matter, but not in gray matter, additional studies are required to determine whether this dichotomy is a consequence of intrinsic differences between fibrous and protoplasmic astroglia in response to inflammation, or of the greater intensity of inflammation in white than gray matter in EAE (Soulika et al., 2009). It will be especially interesting to determine whether there are also differences between these two astroglial populations with respect to metabolic features of the reactive astroglial phenotype (e.g., chemokine induction and perturbations in glutamate homeostasis) known to play roles in the pathophysiology of multiple sclerosis and EAE (Sofroniew, 2009; Holman et al., 2011).

\section{Conclusions}

Spinal cord OPCs, though produced in increased numbers during EAE, are not diverted to astrogenesis, nor are spinal cord ependymal cells (Fig. 10). Instead, reactive astrogliosis is largely or solely a consequence of phenotypic transformation of postmitotic protoplasmic astroglia in spinal cord gray matter, and of proliferation and phenotypic transformation of fibrous astroglia in spinal cord white matter (Fig. 10). Resident spinal cord astrocytes and ependymal cells are restricted to their own lineages in this multiple sclerosis model (Fig. 10). Our study also provides an overall view of the plasticity of OPCs, ependyma, and astroglia (Fig. 10). Further studies will be required to assess lineage relationships between OPCs and Olig2 ${ }^{+}$ protoplasmic astroglia during normal spinal cord development.

\section{References}

Alonso G (2005) NG2 proteoglycan-expressing cells of the adult rat brain: possible involvement in the formation of glial scar astrocytes following stab wound. Glia 49:318-338.

Bannerman P, Hahn A, Soulika A, Gallo V, Pleasure D (2007) Astrogliosis in EAE spinal cord: derivation from radial glia, and relationships to oligodendroglia. Glia 55:57-64.

Barnabé-Heider F, Göritz C, Sabelström H, Takebayashi H, Pfrieger FW, Meletis K, Frisén J (2010) Origin of new glial cells in intact and injured adult spinal cord. Cell Stem Cell 7:470-482.

Bebo BF Jr, Dehghani B, Foster S, Kurniawan A, Lopez FJ, Sherman LS (2009) Treatment with selective estrogen receptor modulators regulates 
myelin specific T-cells and suppresses experimental autoimmune encephalomyelitis. Glia 57:777-790.

Brundin L, Brismar H, Danilov AI, Olsson T, Johansson CB (2003) Neural stem cells: a potential source for remyelination in neuroinflammatory disease. Brain Pathol 13:322-328.

Buffo A, Vosko MR, Ertürk D, Hamann GF, Jucker M, Rowitch D, Götz M (2005) Expression pattern of the transcription factor Olig2 in response to brain injuries: implications for neuronal repair. Proc Natl Acad Sci U S A 102:18183-18188.

Buffo A, Rite I, Tripathi P, Lepier A, Colak D, Horn AP, Mori T, Götz M (2008) Origin and progeny of reactive gliosis: a source of multipotent cells in the injured brain. Proc Natl Acad Sci U S A 105:3581-3586.

Bush TG, Puvanachandra N, Horner CH, Polito A, Ostenfeld T, Svendsen CN, Mucke L, Johnson MH, Sofroniew MV (1999) Leukocyte infiltration, neuronal degeneration, and neurite outgrowth after ablation of scarforming, reactive astrocytes in adult transgenic mice. Neuron 23:297-308.

Bushong EA, Martone ME, Jones YZ, Ellisman MH (2002) Protoplasmic astrocytes in CA1 stratum radiatum occupy separate anatomical domains. J Neurosci 22:183-192.

Carlén M, Meletis K, Göritz C, Darsalia V, Evergren E, Tanigaki K, Amendola M, Barnabé-Heider F, Yeung MS, Naldini L, Honjo T, Kokaia Z, Shupliakov O, Cassidy RM, Lindvall O, Frisén J (2009) Forebrain ependymal cells are Notch-dependent and generate neuroblasts and astrocytes after stroke. Nat Neurosci 12:259-267.

Cassiani-Ingoni R, Coksaygan T, Xue H, Reichert-Scrivner SA, Wiendl H, Rao MS, Magnus T (2006) Cytoplasmic translocation of Olig2 in adult glial progenitors marks the generation of reactive astrocytes following autoimmune inflammation. Exp Neurol 201:349-358.

Charcot JM (1877) Lectures on the diseases of the nervous system. 1-2:180.

Chen Y, Miles DK, Hoang T, Shi J, Hurlock E, Kernie SG, Lu QR (2008) The basic helix-loop-helix transcription factor olig2 is critical for reactive astrocyte proliferation after cortical injury. J Neurosci 28:10983-10989.

Danilov AI, Covacu R, Moe MC, Langmoen IA, Johansson CB, Olsson T, Brundin L (2006) Neurogenesis in the adult spinal cord in an experimental model of multiple sclerosis. Eur J Neurosci 23:394-400.

Faulkner JR, Herrmann JE, Woo MJ, Tansey KE, Doan NB, Sofroniew MV (2004) Reactive astrocytes protect tissue and preserve function after spinal cord injury. J Neurosci 24:2143-2155.

Ganat YM, Silbereis J, Cave C, Ngu H, Anderson GM, Ohkubo Y, Ment LR, Vaccarino FM (2006) Early postnatal astroglial cells produce multilineage precursors and neural stem cells in vivo. J Neurosci 26:8609-8621.

Guo F, Ma J, McCauley E, Bannerman P, Pleasure D (2009) Early postnatal proteolipid promoter-expressing progenitors produce multilineage cells in vivo. J Neurosci 29:7256-7270.

Guo F, Maeda Y, Ma J, Xu J, Horiuchi M, Miers L, Vaccarino F, Pleasure D (2010) Pyramidal neurons are generated from oligodendroglial progenitor cells in adult piriform cortex. J Neurosci 30:12036-12049.

Hamilton LK, Truong MK, Bednarczyk MR, Aumont A, Fernandes KJ (2009) Cellular organization of the central canal ependymal zone, a niche of latent neural stem cells in the adult mammalian spinal cord. Neuroscience 164:1044-1056.

Holman DW, Klein RS, Ransohoff RM (2011) The blood-brain barrier, chemokines and multiple sclerosis. Biochim Biophys Acta 1812:220-230.

Horner PJ, Thallmair M, Gage FH (2002) Defining the NG2-expressing cell of the adult CNS. J Neurocytol 31:469-480.

Huizinga R, Gerritsen W, Heijmans N, Amor S (2008) Axonal loss and gray matter pathology as a direct result of autoimmunity to neurofilaments. Neurobiol Dis 32:461-470.

Kang SH, Fukaya M, Yang JK, Rothstein JD, Bergles DE (2010) NG2+ CNS glial progenitors remain committed to the oligodendrocyte lineage in postnatal life and following neurodegeneration. Neuron 68:668-681.

Komitova M, Serwanski DR, Richard Lu QR, Nishiyama A (2011) NG2 cells are not a major source of reactive astrocytes after neocortical stab wound injury. Glia 59:800-809.

Lagace DC, Whitman MC, Noonan MA, Ables JL, DeCarolis NA, Arguello AA, Donovan MH, Fischer SJ, Farnbauch LA, Beech RD, DiLeone RJ, Greer CA, Mandyam CD, Eisch AJ (2007) Dynamic contribution of nestin-expressing stem cells to adult neurogenesis. J Neurosci 27:12623-12629.

Lang B, Liu HL, Liu R, Feng GD, Jiao XY, Ju G (2004) Astrocytes in injured adult rat spinal cord may acquire the potential of neural stem cells. Neuroscience 128:775-783.
Ligon KL, Kesari S, Kitada M, Sun T, Arnett HA, Alberta JA, Anderson DJ, Stiles CD, Rowitch DH (2006) Development of NG2 neural progenitor cells requires Olig gene function. Proc Natl Acad Sci U S A 103:7853-7858.

Magnus T, Coksaygan T, Korn T, Xue H, Arumugam TV, Mughal MR, Eckley DM, Tang SC, Detolla L, Rao MS, Cassiani-Ingoni R, Mattson MP (2007) Evidence that nucleocytoplasmic Olig2 translocation mediates braininjury-induced differentiation of glial precursors to astrocytes. J Neurosci Res 85:2126-2137.

Magnus T, Carmen J, Deleon J, Xue H, Pardo AC, Lepore AC, Mattson MP, Rao MS, Maragakis NJ (2008) Adult glial precursor proliferation in mutant SOD1G93A mice. Glia 56:200-208.

Marichal N, García G, Radmilovich M, Trujillo-Cenóz O, Russo RE (2009) Enigmatic central canal contacting cells: immature neurons in "standby mode"? J Neurosci 29:10010-10024.

Marshall CA, Novitch BG, Goldman JE (2005) Olig2 directs astrocyte and oligodendrocyte formation in postnatal subventricular zone cells. J Neurosci 25:7289-7298.

Meletis K, Barnabé-Heider F, Carlén M, Evergren E, Tomilin N, Shupliakov O, Frisén J (2008) Spinal cord injury reveals multilineage differentiation of ependymal cells. PLoS Biol 6:e182.

Miron VE, Kuhlmann T, Antel JP (2011) Cells of the oligodendroglial lineage, myelination, and remyelination. Biochim Biophys Acta 1812:184-193.

Mirzadeh Z, Merkle FT, Soriano-Navarro M, Garcia-Verdugo JM, AlvarezBuylla A (2008) Neural stem cells confer unique pinwheel architecture to the ventricular surface in neurogenic regions of the adult brain. Cell Stem Cell 3:265-278.

Myer DJ, Gurkoff GG, Lee SM, Hovda DA, Sofroniew MV (2006) Essential protective roles of reactive astrocytes in traumatic brain injury. Brain 129:2761-2772.

Rawlins EL, Ostrowski LE, Randell SH, Hogan BL (2007) Lung development and repair: contribution of the ciliated lineage. Proc Natl Acad Sci U S A 104:410-417.

Rivers LE, Young KM, Rizzi M, Jamen F, Psachoulia K, Wade A, Kessaris N, Richardson WD (2008) PDGFRA/NG2 glia generate myelinating oligodendrocytes and piriform projection neurons in adult mice. Nat Neurosci 11:1392-1401.

Robel S, Berninger B, Götz M (2011) The stem cell potential of glia: lessons from reactive gliosis. Nat Rev Neurosci 12:88-104.

Sellers DL, Maris DO, Horner PJ (2009) Postinjury niches induce temporal shifts in progenitor fates to direct lesion repair after spinal cord injury. J Neurosci 29:6722-6733.

Sofroniew MV (2009) Molecular dissection of reactive astrogliosis and glial scar formation. Trends Neurosci 32:638-647.

Soulika AM, Lee E, McCauley E, Miers L, Bannerman P, Pleasure D (2009) Initiation and progression of axonopathy in experimental autoimmune encephalomyelitis. J Neurosci 29:14965-14979.

Srinivas S, Watanabe T, Lin CS, William CM, Tanabe Y, Jessell TM, Costantini F (2001) Cre reporter strains produced by targeted insertion of EYFP and ECFP into the ROSA26 locus. BMC Dev Biol 1:4.

Takahashi M, Arai Y, Kurosawa H, Sueyoshi N, Shirai S (2003) Ependymal cell reactions in spinal cord segments after compression injury in adult rat. J Neuropathol Exp Neurol 62:185-194.

Takebayashi H, Nabeshima Y, Yoshida S, Chisaka O, Ikenaka K, Nabeshima Y (2002) The basic helix-loop-helix factor olig2 is essential for the development of motoneuron and oligodendrocyte lineages. Curr Biol 12:1157-1163.

Tatsumi K, Takebayashi H, Manabe T, Tanaka KF, Makinodan M, Yamauchi T, Makinodan E, Matsuyoshi H, Okuda H, Ikenaka K, Wanaka A (2008) Genetic fate mapping of Olig2 progenitors in the injured adult cerebral cortex reveals preferential differentiation into astrocytes. J Neurosci Res 86:3494-3502.

Tripathi RB, Rivers LE, Young KM, Jamen F, Richardson WD (2010) NG2 glia generate new oligodendrocytes but few astrocytes in a murine experimental autoimmune encephalomyelitis model of demyelinating disease. J Neurosci 30:16383-16390.

Voskuhl RR, Peterson RS, Song B, Ao Y, Morales LB, Tiwari-Woodruff S, Sofroniew MV (2009) Reactive astrocytes form scar-like perivascular barriers to leukocytes during adaptive immune inflammation of the CNS. J Neurosci 29:11511-11522. 
Wu J, Ohlsson M, Warner EA, Loo KK, Hoang TX, Voskuhl RR, Havton LA (2008) Glial reactions and degeneration of myelinated processes in spinal cord gray matter in chronic experimental autoimmune encephalomyelitis. Neuroscience 156:586-596.

Yamaguchi M, Saito H, Suzuki M, Mori K (2000) Visualization of neurogenesis in the central nervous system using nestin promoter-GFP transgenic mice. Neuroreport 11:1991-1996.

Young KM, Mitsumori T, Pringle N, Grist M, Kessaris N, Richardson WD (2010) An Fgfr3-iCreER(T2) transgenic mouse line for studies of neural stem cells and astrocytes. Glia 58:943-953.

Zawadzka M, Rivers LE, Fancy SP, Zhao C, Tripathi R, Jamen F, Young K, Goncharevich A, Pohl H, Rizzi M, Rowitch DH, Kessaris N, Suter U,
Richardson WD, Franklin RJ (2010) CNS-resident glial progenitor/ stem cells produce Schwann cells as well as oligodendrocytes during repair of CNS demyelination. Cell Stem Cell 6:578-590.

Zhu X, Hill RA, Nishiyama A (2008) NG2 cells generate oligodendrocytes and gray matter astrocytes in the spinal cord. Neuron Glia Biol $4: 19-26$.

Zhu X, Hill RA, Dietrich D, Komitova M, Suzuki R, Nishiyama A (2011) Age-dependent fate and lineage restriction of single NG2 cells. Development 138:745-753.

Zhuo L, Sun B, Zhang CL, Fine A, Chiu SY, Messing A (1997) Live astrocytes visualized by green fluorescent protein in transgenic mice. Dev Biol 187: $36-42$. 